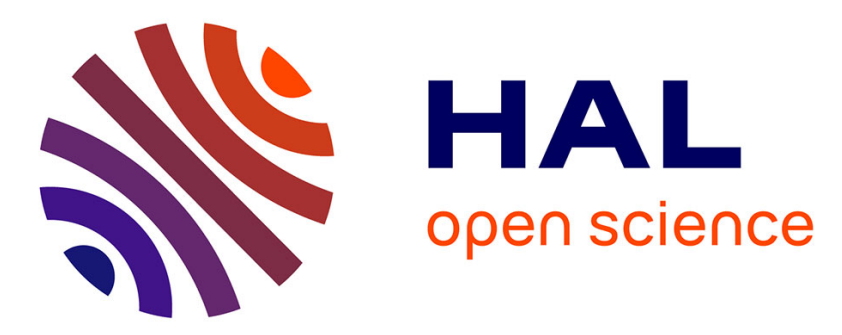

\title{
Modelling, identification and application of phenomenological constitutive laws over a large strain rate and temperature range
}

Anis Hor, Franck Morel, Jean-Lou Lebrun, Guénaël Germain

\section{To cite this version:}

Anis Hor, Franck Morel, Jean-Lou Lebrun, Guénaël Germain. Modelling, identification and application of phenomenological constitutive laws over a large strain rate and temperature range. Mechanics of Materials, 2013, 64, pp.91-110. 10.1016/j.mechmat.2013.05.002 . hal-01068551

\section{HAL Id: hal-01068551 \\ https://hal.science/hal-01068551}

Submitted on 25 Sep 2014

HAL is a multi-disciplinary open access archive for the deposit and dissemination of scientific research documents, whether they are published or not. The documents may come from teaching and research institutions in France or abroad, or from public or private research centers.
L'archive ouverte pluridisciplinaire HAL, est destinée au dépôt et à la diffusion de documents scientifiques de niveau recherche, publiés ou non, émanant des établissements d'enseignement et de recherche français ou étrangers, des laboratoires publics ou privés. 


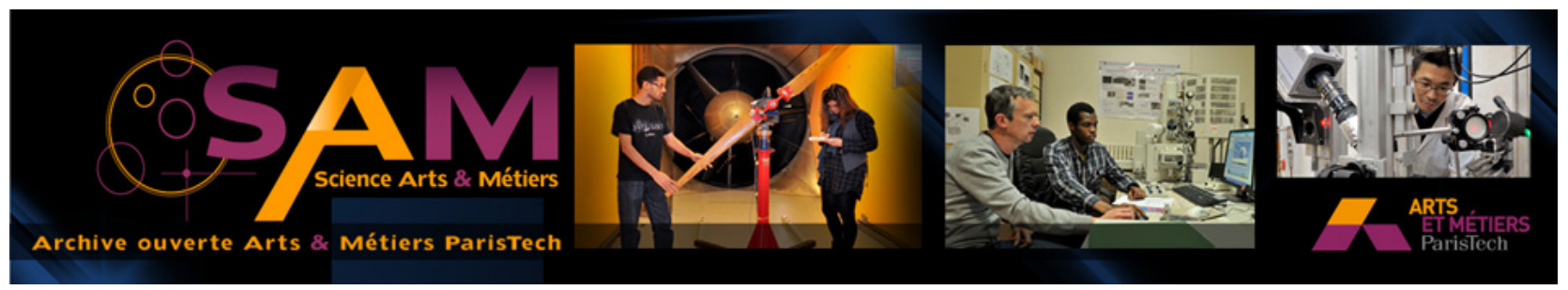

\section{Science Arts \& Métiers (SAM)}

is an open access repository that collects the work of Arts et Métiers ParisTech researchers and makes it freely available over the web where possible.

This is an author-deposited version published in: http://sam.ensam.eu

Handle ID: .http://hdl.handle.net/10985/8619

\section{To cite this version :}

Anis HOR, Franck MOREL, Jean-Lou LEBRUN, Guénaël GERMAIN - Modelling, identification and application of phenomenological constitutive laws over a large strain rate and temperature range - Mechanics of Materials - Vol. 64, p.91-110 - 2013 


\title{
Modelling, identification and application of phenomenological constitutive laws over a large strain rate and temperature range
}

\author{
Anis Hor*, Franck Morel, Jean-Lou Lebrun, Guénaël Germain \\ Arts et Métiers ParisTech, CER Angers, Laboratoire LAMPA, 2 Bd du Ronceray, 49035 Angers Cedex 1, France
}

Keywords:

Rheology

Large strain rate and temperature range

$42 \mathrm{CrMo} 4$

$100 \mathrm{Cr} 6$

Identification

Numerical simulation

\begin{abstract}
A B S T R A C T
A review of the different phenomenological thermo-viscoplastic constitutive models often applied to forging and machining processes is presented. Several of the most common models have been identified using a large experimental database (Hor et al., 2013). The latter consists of the tests were done in compression on cylindrical shaped specimens and in shear using hat-shaped specimens. The comparison between these different models is shown that the group of decoupled empirical constitutive models (e.g. the Johnson and Cook (1983) model), despite their simple identification procedures, are relatively limited, especially over a large range of strain rates and temperatures. Recent studies have led to the proposal of coupled empirical models. Three models in this class have also been studied. The Lurdos (2008) model shows the best accuracy but requires a large experimental database to identify its high number of parameters. After this comparison, a constitutive equation is proposed by modifying the TANH model (Calamaz et al., 2010). Coupling between the effects of strain rate and temperature is introduced. This model is easier to identify and does not require knowledge of the saturation stress. Compared to other models, it better reproduces the experimental results especially in the semi-hot and hot domains.

In order to study real machining conditions, an orthogonal cutting tests is considered. The comparison between experimental test results and numerical simulations conducted using the previously identified constitutive models shows that the decoupled empirical models are not capable of reproducing the experimental observations. However, the coupled constitutive models, that take into account softening, improve the accuracy of these simulations.
\end{abstract}

\section{Introduction}

In order to correctly study rheology in forging and machining operations a wide range of strain rates (between $10^{-2}$ and $10^{5} \mathrm{~s}^{-1}$ ) and temperatures (up to the melting temperature) must be taken into account (Hor et al., 2013). Over this large range of rheological variables, the investigated steels are subject to phenomena accompanying deformation such as strain hardening, softening and

\footnotetext{
* Corresponding author. Tel.: +33 (0)241207336; fax: +33 (0)241207320.

E-mail address: anis.hor@ensam.eu (A. Hor).
}

phase changes (Hor et al., 2013). These phenomena affect the overall material behaviour and result in a change in the shape of the stress-strain curves. To model the thermo-viscoplastic behaviour, many constitutive models exist. Most were developed using the assumption of isotropic behaviour. The general form of these models can be written as:

$\sigma=\sigma\left(\dot{\varepsilon}, T, \alpha_{i}\right) \quad$ and $\quad \alpha_{i}=\alpha_{i}\left(\sigma, \dot{\varepsilon}, T, \alpha_{j}\right)$

The stress and strain rate tensors are usually replaced by the von Mises equivalent stress and strain rate (given by $\sigma$ and $\dot{\varepsilon}$ respectively). One or more internal variables (noted $\alpha_{i}$ ) are used to take into account more accurately 
the deformation history and the physical parameters of the studied material (deformation, dislocation density, grain size, etc.). In general, it is the evolution laws $\frac{d \alpha_{i}}{d t}$ of the internal variables that are defined.

Stress-strain constitutive models fall into three categories: empirical models, semi-empirical models and models incorporating physical phenomena. The latter are the most evolved, they offer solutions that are based on the physics of deformation processes, but are often more complex to use. Internal variables represent the deformation history and/or characteristics sizes of the physical state of the material (i.e. grain size, dislocation density, etc.). The Kocks and Mecking model (Kocks, 1976) and the Bergström et al. model (Bergstrom and Roberts, 1971) can be cited as examples of this class of models, describing the evolution of the density of mobile (or all) dislocations to account for the hardening and restoration of the material. Semi-empirical models can be defined as having a simple formulation while incorporating the minimum physical phenomenon. Although, they do not contain internal variables. They have an additive form which regroups an athermal part and a thermal part making reference to thermally activated phenomena. Include in this category are the Klepaczko model (Klepaczko, 1987) and the Zerilli and Armstrong model (Zerilli and Armstrong, 1987). These two classes of constitutive models are used primarily by metallurgists to reflect the evolution of certain phenomena during manufacturing processes (recrystallization, twinning, etc.), but rarely to simulate the thermo-mechanical behaviour of materials during these processes. Unlike empirical models, which generally have a simple formulation. Only a few tests are required to identify their coefficients. Moreover, their mathematical form is chosen so as to facilitate their implementation in numerical software. This allows calculations to be undertaken at low computational and experimental cost. These two benefits explain why empirical models are very often used. These models have undergone several developments in recent years with advances in numerical and experimental methods.

In this work, the predictive power of these different empirical models is tested in terms of machining and forging operations while outlining the experimental and numerical difficulties encountered in their identification. This is done by using a large experimental stress-strain database (Fig. 1) of three steels: the 42CrMo4 steel with two different microstructures, ferrito-perlitic and bainitic (referred to as 42CrMo4-FP and 42CrMo4-BA respectively) and the $100 \mathrm{Cr} 6$ steel (referred to as $100 \mathrm{Cr} 6-\mathrm{FP}$ ). This experimental database is widely detailed in Hor et al. (2013). Then, a coupled empirical model with a better cost/accuracy ratio is proposed. Finally, the value of using more accurate models will be discussed through the numerical simulations of orthogonal cutting.

\section{Experimental database}

In this section, the material behaviour will be briefly analysed for both loading cases (compression and shear) in terms of strain rate and temperature sensitivity on the flow stress. This analysis only focuses on 42CrMo4-BA steel, a more detailed study is provided for the three studied steels in Hor et al. (2013). The results for the compression and shear tests for the $42 \mathrm{CrMo} 4-\mathrm{BA}$ steel are given in Fig. 2. The experimental procedure and the determination of the different variables (stress, shear stress, plastic strain and plastic shear strain) are described in Hor et al. (2013).

From Fig. 2(a), it can be seen that, for a given strain rate $\left(10^{-2} \mathrm{~s}^{-1}\right)$, a temperature rise moved the stress-plastic strain curves towards the bottom. A radical change could be observed in the shape of these curves. Their slopes can be both positive, indicating work hardening, or negative indicating softening. With respect to this competition between work hardening and softening, three deformation domains can be distinguished, as a function of the temperature. These observations remain valid for the shear loading mode (Fig. 2(b)). Although the attained shear levels were very high (up to 6 in von Mises equivalent strain), a saturation stress was observed only for some temperature and equivalent strain rate conditions.

\subsection{Cold deformation domain $\left(T / T_{f}<0.3\right)$}

In this domain, work hardening is the phenomenon observed for low strain rates (up to $1 \mathrm{~s}^{-1}$ ). Increasing the strain rate led to the appearance of softening (Fig. 3(a1)). This phenomenon can appear after a change in the deformation mechanism caused by the speed of the deformation process. Besides, during dynamic tests $\left(\dot{\varepsilon} \geqslant 1 \mathrm{~s}^{-1}\right)$, the plastic power was converted into heat which could not be evacuated in this range of strain rate. This phenomenon will be called self-heating. (a) 42CrMo4-FP

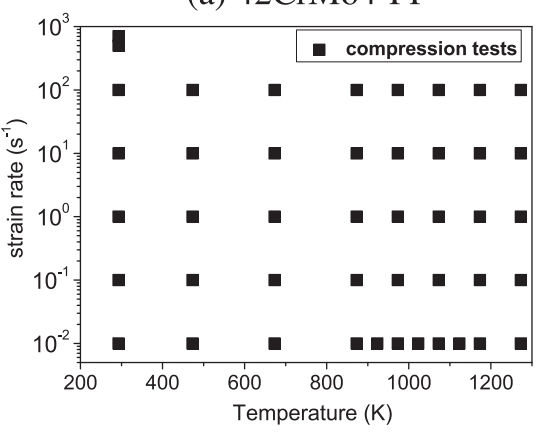

(b) 42CrMo4-BA

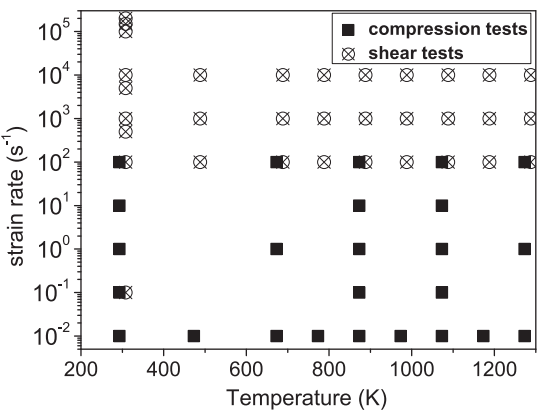

(c) 100Cr6-FP

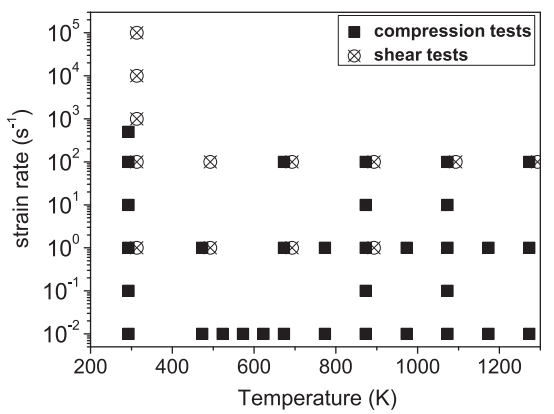

Fig. 1. Thermo-mechanical testing conditions of the three steels investigated. 
(a) Compression tests

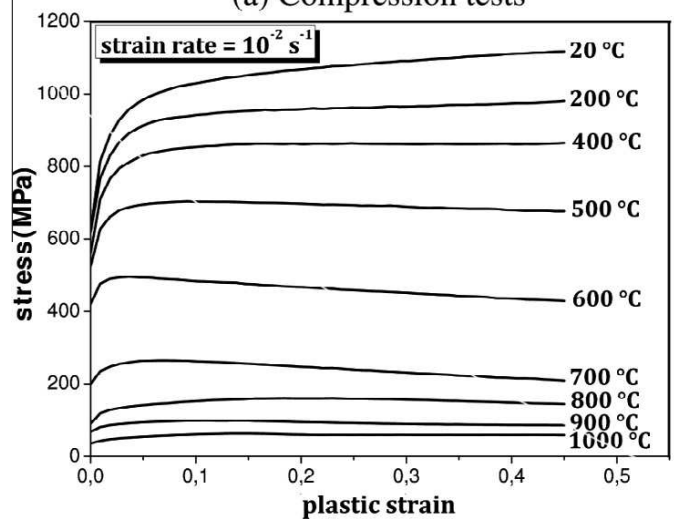

(b) Shear tests

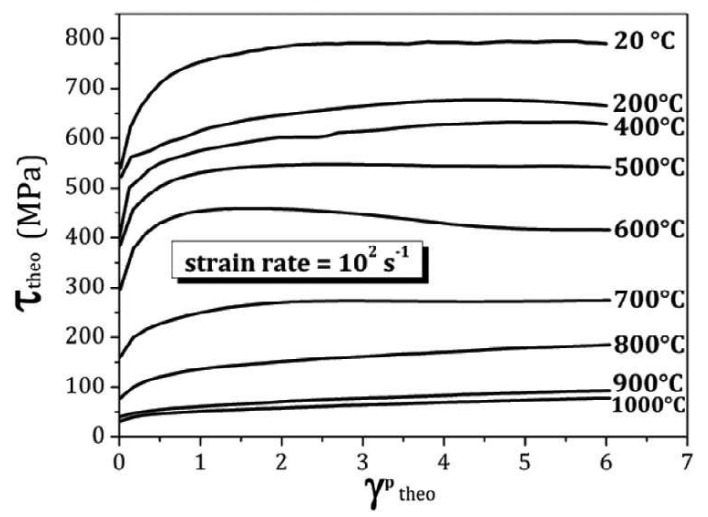

Fig. 2. Evolution of (a) the compressive stress as a function of the plastic strain at a strain rate of $10^{-2} \mathrm{~s}^{-1}$ and (b) the shear stress as a function of the plastic shear strain at an equivalent strain rate of $10^{2} \mathrm{~s}^{-1}$ for the $42 \mathrm{CrMo} 4-\mathrm{BA}$ steel.

(a) Compression loading

(a1) $T / T_{f}<0.3$

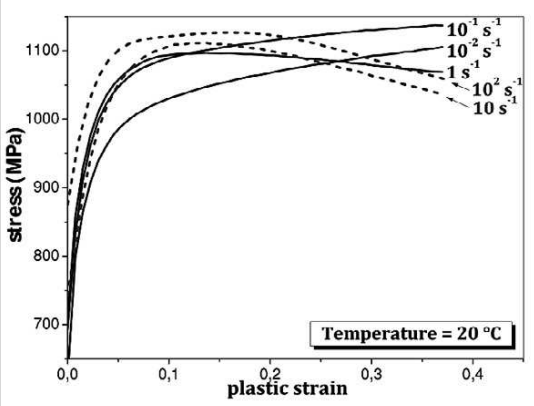

(b1) $T / T_{f}<0.3$

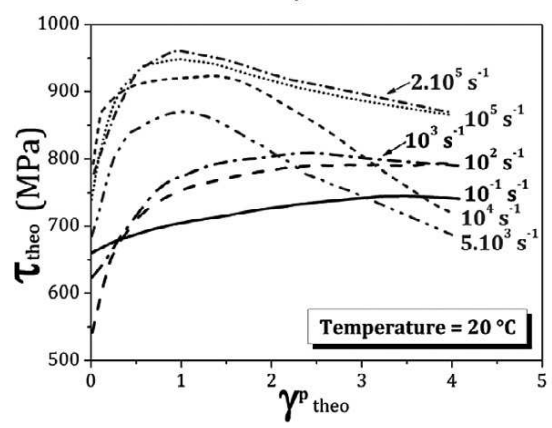

(a2) $0.3 \leq T / T_{f} \leq 0.5$

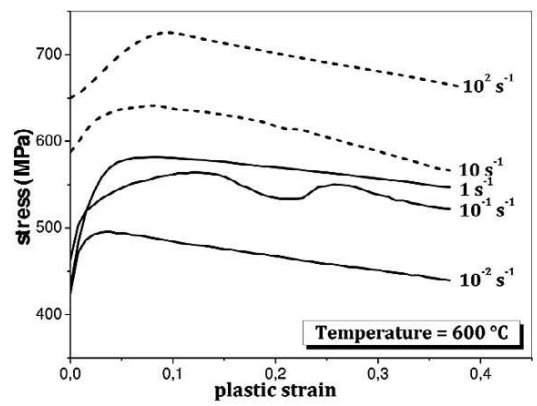

(b) Shear loading

(b2) $0.3 \leq T / T_{f} \leq 0.5$

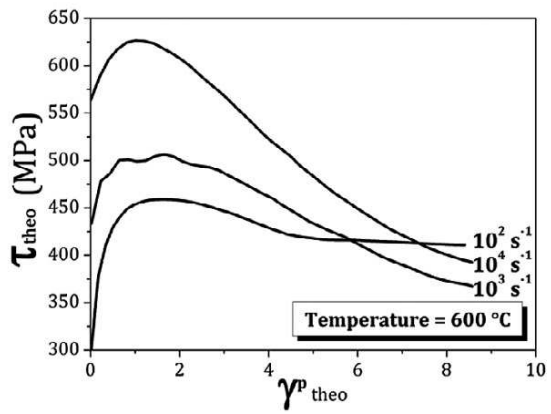

(a3) $T / T_{f}>0.5$

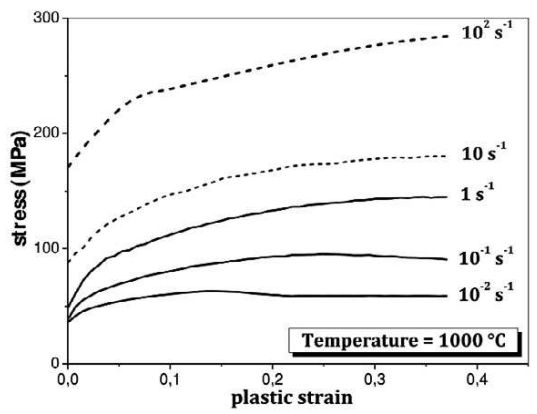

(b3) $T / T_{f}>0.5$

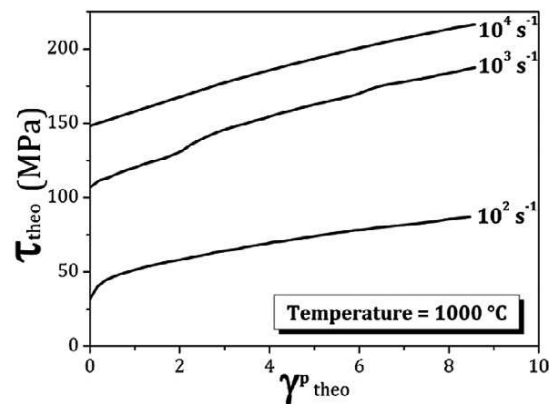

Fig. 3. Evolution of (a) the compressive stress as a function of the plastic strain and (b) the shear stress as a function of the plastic shear strain, at $20{ }^{\circ} \mathrm{C}$, $600{ }^{\circ} \mathrm{C}$ and $1000{ }^{\circ} \mathrm{C}$, for different equivalent strain rates for the $42 \mathrm{CrMo} 4-\mathrm{BA}$ steel.

For the shear tests, the stress increased with the equivalent strain rate. For equivalent strain rates between $10^{-1}$ and $10^{3} \mathrm{~s}^{-1}$, the increase was modest. Above $10^{3} \mathrm{~s}^{-1}$, the rate sensitivity became important and the shape of the curves was also changed (see Fig. 3(b1)). From an equivalent strain rate of $10^{3} \mathrm{~s}^{-1}$, the stresses reached a local maximum and then decreased gradually. Damage was not observed in this case. This softening was also due to selfheating.

To evaluate the level of self-heating, the evolution of temperature was measured at the surface of the specimen subjected to compression loading at an initial temperature of $20^{\circ} \mathrm{C}$ and at a strain rate of $\dot{\varepsilon}=10^{2} \mathrm{~s}^{-1}$. The evolutions of temperature and strain as function of test time are plotted in Fig. 4. An increase in the surface temperature of approximately $120^{\circ} \mathrm{C}$ was measured during the test, and it is very likely that the temperature in the centre of the specimen was higher. This is reinforced by the observed time difference between the strain evolution and the appearance of a high surface temperature. A non-negligible time period was necessary for the surface temperature to increase. This phenomenon caused the flow stress to decrease at the end 


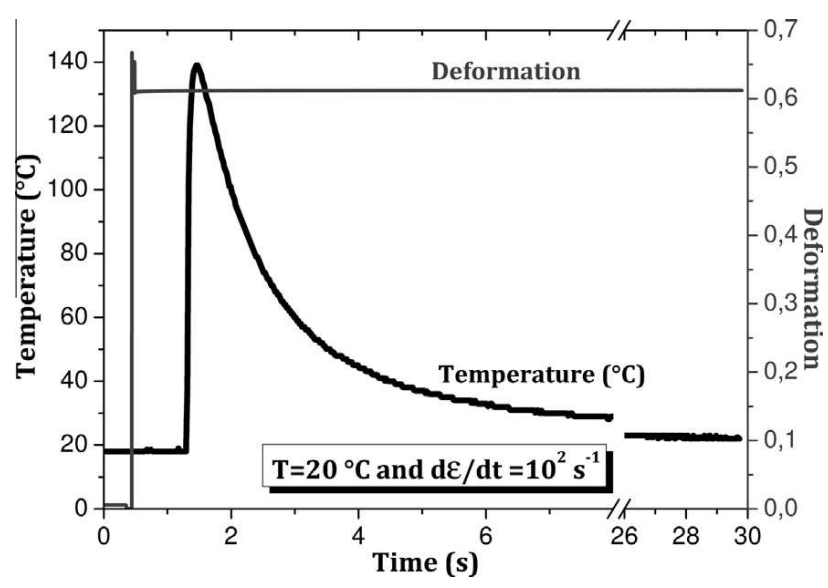

Fig. 4. Experimental measurement of the temperature increase during compression deformation of the $42 \mathrm{CrMo} 4-\mathrm{BA}$ steel at $\mathrm{T}=20^{\circ} \mathrm{C}$ and $\dot{\varepsilon}=10^{2} \mathrm{~s}^{-1}$ (Hor et al., 2013).

of the deformation process. In the literature, constitutive models are typically based on isothermal flow curves. Consequently, adiabatic flow curves should be corrected to isothermal flow curves (Hor et al., 2013). Self-heating is therefore a phenomenon that provokes softening and reduces the level of work hardening for steel materials.

Two axisymmetric finite element calculations corresponding to the compression and shear loading conditions were carried out. The models assumed adiabatic flow where the coefficient of the plastic power converted into heat (Taylor-Quinney factor) was 0.95. Abaqus Explicit finite element code was used in conjunction with a Johnson-Cook constitutive law (Johnson and Cook, 1983). The material parameters used were identified from the compression tests (see Table 7 ). Frictional effects were neglected in both cases. The initial temperature was equal to $20^{\circ} \mathrm{C}(293 \mathrm{~K})$. Two speeds $\left(10^{-2} \mathrm{~ms}^{-1}\right.$ and $\left.1 \mathrm{~ms}^{-1}\right)$ were applied on the top face of the specimen in the $(-Y)$ direction. These two speeds respectively corresponded to an average strain rate of $1 \mathrm{~s}^{-1}$ and $10^{2} \mathrm{~s}^{-1}$ in compression and $10^{2} \mathrm{~s}^{-1}$ and $10^{4} \mathrm{~s}^{-1}$ in shear. The bottom face was fixed. For the compression simulation $\left(T=20^{\circ} \mathrm{C}\right.$, $\dot{\varepsilon}=10^{2} \mathrm{~s}^{-1}$ ), the surface temperature (at the node corresponding to the thermocouples location) reached $135^{\circ} \mathrm{C}$, to compare with $140^{\circ} \mathrm{C}$ obtained experimentally in the same conditions (Fig. 4). The temperature at the centre of the specimen reached $200{ }^{\circ} \mathrm{C}(473 \mathrm{~K})$ for a speed of $1 \mathrm{~ms}^{-1}$ or $110{ }^{\circ} \mathrm{C}(383 \mathrm{~K})$ for a speed of $10^{-2} \mathrm{~ms}^{-1}$. In the case of the shear simulation, the self-heating temperature was higher than the temperature reached in compression $\left(300{ }^{\circ} \mathrm{C} / 573 \mathrm{~K}\right.$ ) and more localized (Fig. 5(b)). This localization was more pronounced for the highest speed $\left(1 \mathrm{~ms}^{-1}\right)$. The temperature numerically calculated was lower than the temperature causing adiabatic shear bands (Meyers et al., 1994). These bands were not experimentally observed.

In Hor et al. (2013), comparison was done between isothermal, adiabatic (present simulation) and experimental (data in Fig. 3(a1)) flow curves. The softening observed experimentally was reproduced only in adiabatic flow simulation. However, the relative differences between the two simulated flow stresses remained low (below 7\%). These differences will be taken into account at the step of identification.

\subsection{Semi-hot deformation domain $\left(0.3 \leqslant T / T_{f} \leqslant 0.5\right)$}

The phenomenon which dominated in this domain for all strain rates is softening (see Fig. 3(a2)). The strain rate did not have an influence on the amount of softening but rather on the stress level. This structural softening was not provoked by self-heating but rather by a change in the deformation mechanisms. The dislocation mobility was perturbed by thermally activated phenomena such as dynamic recrystallisation (Hor et al., 2013). These phenomena appeared even more clearly in the 42CrMO4-BA steel where oscillations in the stress-strain curve were observed $\left(T=600^{\circ} \mathrm{C}\right.$ and $\left.\dot{\varepsilon}=10^{-1} \mathrm{~s}^{-1}\right)$. Finally, with respect to the cold deformation domain, the flow stress was more sensitive to the strain rate.

For the shear tests, for all equivalent strain rates, the shear stress-strain curves were displayed by a local maximum followed by a decrease in the flow stress towards a saturation stress (see Fig. 3(b2)). The rate of this softening, increased with increasing equivalent strain rate. This was attributed to the effect of the very localized self-heating in the shear zone of the specimen. This phenomenon was not observed in compression, not only because the strain and the strain rates were lower, but also because the strain field in compression test was more homogeneous and the self-heating was less intense and less localized.

\subsection{Hot deformation domain $\left(T / T_{f}>0.5\right)$}

The austenization temperature was between 800 and $900{ }^{\circ} \mathrm{C}$. At these temperatures, the material started to transform from a body centred cubic (BCC) structure to a face centred cubic (FCC) structure (Hor et al., 2013). In this temperature interval, the shape of the stress-strain curves changed completely for the compression and shear loading cases (see Fig. 3(a3) and (b3)). The stress was more sensitive to the strain rate than in the cold and semi-hot deformation domains. Like in the cold domain, the strain rate had an influence on the competition between work hardening and softening. The effect is opposite to the one observed in the first temperature interval, that is, the higher the strain rate, the lower the level of softening and the higher the work hardening. Also, softening that occured at lower strain rates was different to that observed in the cold and semi-hot deformation domains.

\subsection{Syntheses}

The investigation of the material behaviour of the 42CrMo4-BA steel over a large range of strain rates and temperatures, for two loading modes (i.e. compression and shear), highlighted the existence of three deformation domains (cold, semi-hot and hot deformation) that can be defined by certain temperature ranges. The shape of the stress-strain curves and the evolution of the flow stress as a function of the temperature were very different in each domain. As well as the influence on the flow stress, 
(a) Compression test simulation
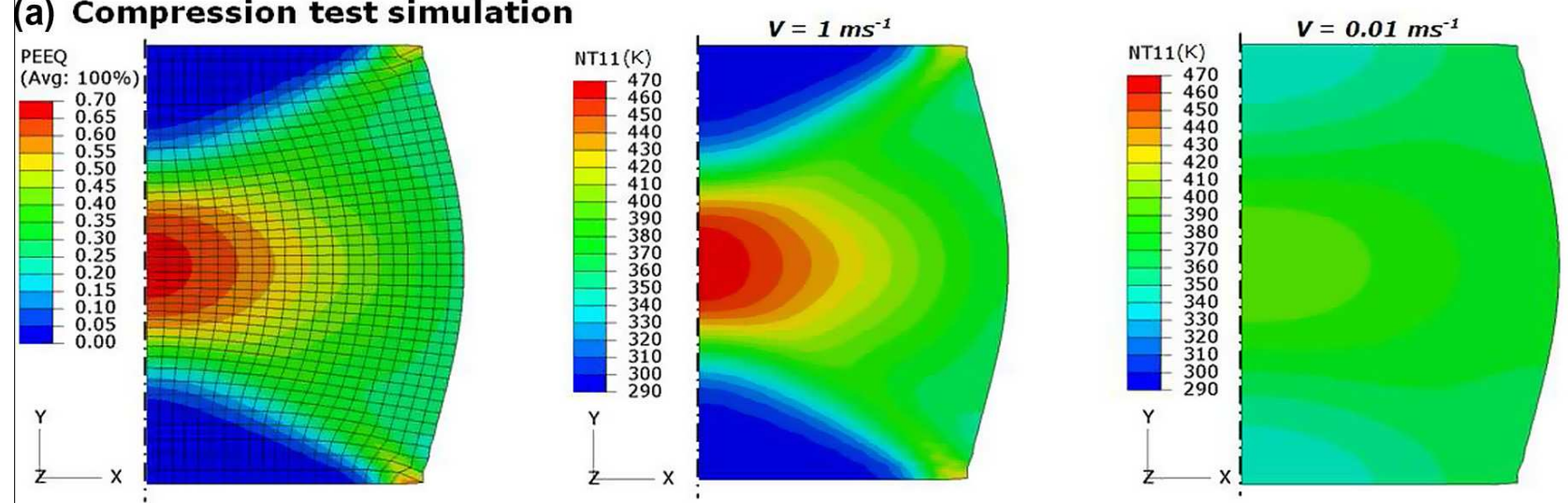

\section{(b) Shear test simulation}
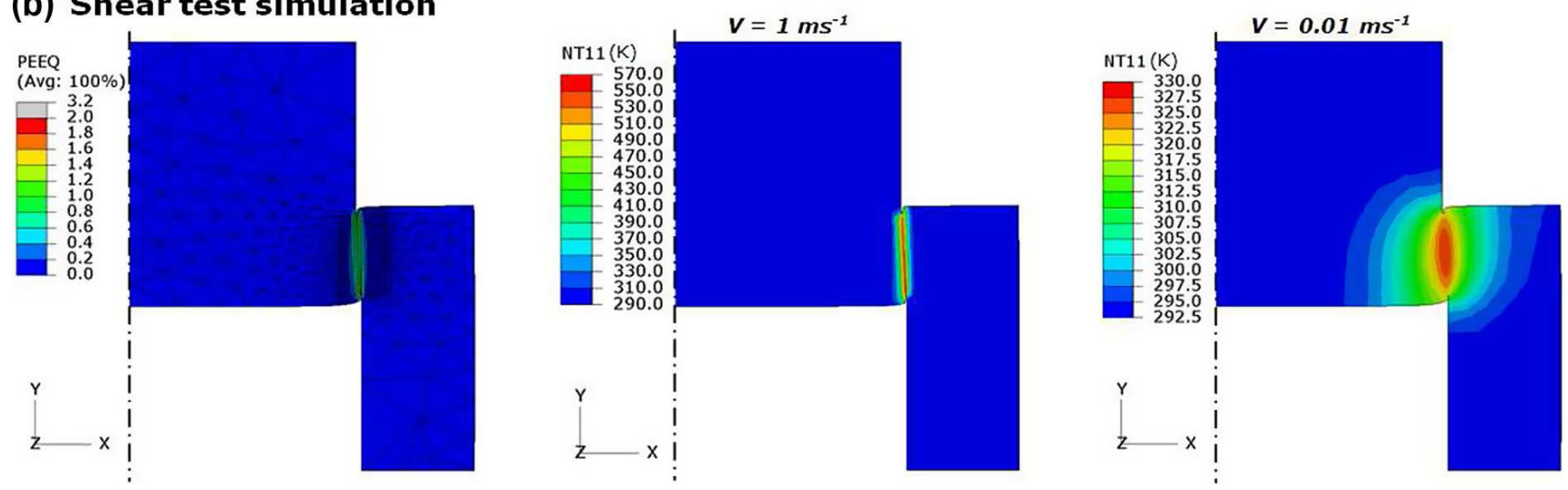

Fig. 5. Self-heating temperature fields obtained by numerical simulation of the (a) compression and (b) shear tests for two speeds ( 1 and $10^{-2}$ ms ${ }^{-1}$ ).

the strain rate played a role on the phenomena accompanying plastic deformation such as work hardening and softening. The comparison between the behaviour of the three steels revealed much similarity (see Hor et al., 2013), which was encouraging from a modelling point of view: the development of a general constitutive model which can be identified over such a large range of rheological state variables appeared to be possible. The constitutive model should be able to reproduce the different configurations shown in Fig. 6. For this purpose, two choices are possible:

- The first choice consists in identifying the appropriate constitutive law in each deformation domain. Three different models should be determined, which requires sufficient experimental data in each domain. This would be very costly in terms of experimental work. Besides, the numerical implementation of three models to capture the constitutive law of one single material would be difficult. This strategy will not be selected due to these disadvantages.

- A second choice would be to identify a single constitutive model for the three deformation domains even with a large number of parameters. This would require finding the most comprehensive model whose formulation can reproduce the different configurations shown in Fig. 6.

It is this second choice that will be discussed in the following.

\section{Phenomenological thermo-viscoplastic modelling}

This paragraph lists the most commonly used phenomenological (or empirical) models. The following general notation will be used: $\sigma_{0}$ refers to the yield strength (or the stress corresponding to zero plastic deformation), $\sigma_{s}$ to the saturation stress (when the strain becomes very large). The terms $\varepsilon$ and $\dot{\varepsilon}$ respectively denote the plastic strain and the plastic strain rate. Finally, the various model parameters will be presented as follows: the notations $n, m, p, \ldots$ will be used as exponents, and the coefficients will be noted as $A, B, C, \ldots$..

\subsection{Decoupled models}

In this class, the quasi-static constitutive laws (Table 1) are usually multiplied by factors empirically describing the influence of the temperature and the strain rate. A single mathematical formula then describes the isotropic hardening and the effects of strain rate and temperature. The general form of this class of constitutive equations is:

$\sigma=\sigma_{\varepsilon}(\varepsilon) \sigma_{\dot{\varepsilon}}(\dot{\varepsilon}) \sigma_{T}(T)$

where $\sigma_{\varepsilon}$ is a function chosen from the expressions in Table $1, \sigma_{\dot{\varepsilon}}$ is the factor describing the sensitivity to the strain rate, and $\sigma_{T}$ is the factor describing the influence of the temperature. Different proposed expressions for the functions $\sigma_{\dot{\varepsilon}}$ and $\sigma_{T}$ are listed in Table 2 .

A stress-strain constitutive equation can be constructed by combining the factors most adapted to the problem. 


\begin{tabular}{|c|c|c|c|c|c|}
\hline$T\left({ }^{\circ} \mathrm{C}\right)$ & $\dot{\varepsilon}=10^{-2} s^{-1}$ & $\dot{\varepsilon}=10^{-1} s^{-1}$ & $\dot{\varepsilon}=1 s^{-1}$ & $\dot{\varepsilon}=10 s^{-1}$ & $\dot{\varepsilon}=10^{2} s^{-1}$ \\
\hline 20 & 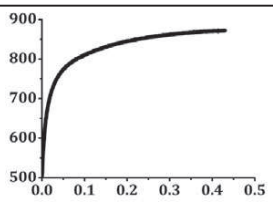 & 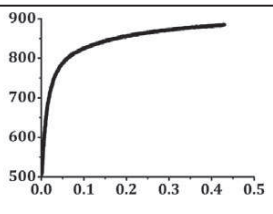 & \begin{tabular}{|ccccccc} 
& & & & & & \\
\end{tabular} & 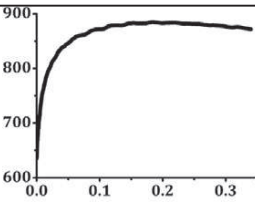 & 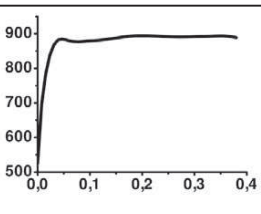 \\
\hline 200 & 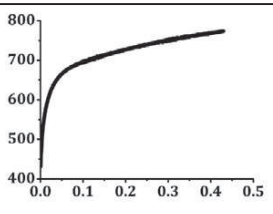 & 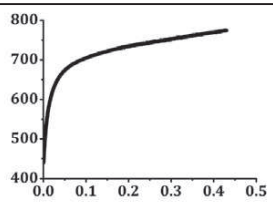 & 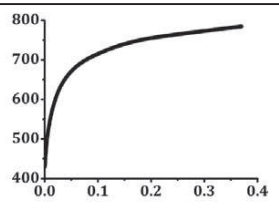 & . & 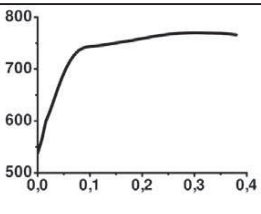 \\
\hline 400 & 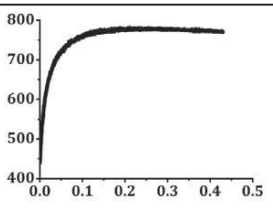 & 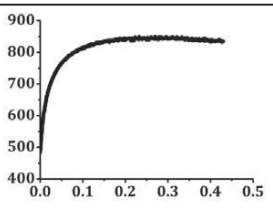 & $\begin{array}{lllllll} & & & & & & \\
\end{array}$ & (250. & $\sqrt{ }$ \\
\hline 600 & 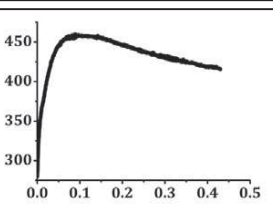 & 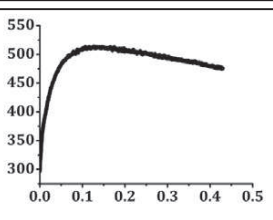 & 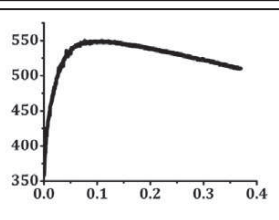 & $\begin{array}{c}650 \\
650 \\
650 \\
550 \\
500 \\
450 \\
400\end{array}$ & 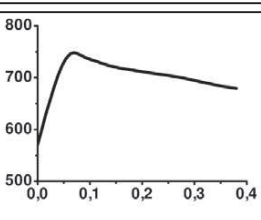 \\
\hline 700 & 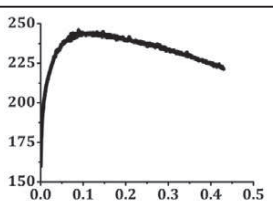 & (250. & (2) & $\begin{array}{llllll}500 & & & & & \\
\end{array}$ & 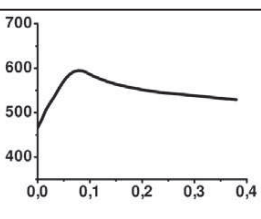 \\
\hline 800 & (10. & 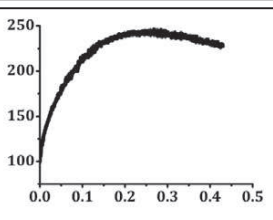 & 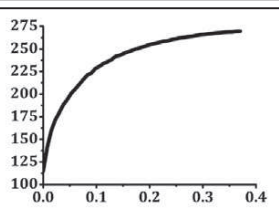 & 焦 & 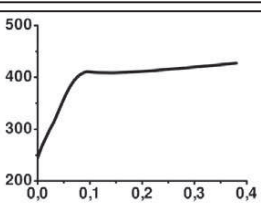 \\
\hline 900 & $\begin{array}{llllllll}0.0 & 0.1 & 0.2 & 0.3 & 0.4 & 0.5\end{array}$ & $\begin{array}{cccccc}50 & & & & \\
0.0 & 0.1 & 0.2 & 0.3 & 0.4 & 0.5\end{array}$ & $\begin{array}{lllll}75 & 0.1 & 0.2 & 0.3 & 0.4\end{array}$ & $\begin{array}{lll}0.1 & 0.2 & 0.3\end{array}$ & 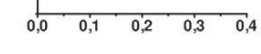 \\
\hline 1000 & 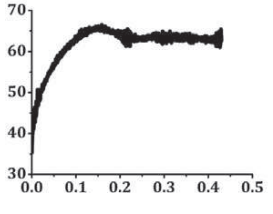 & 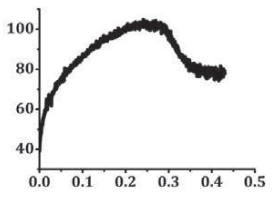 & 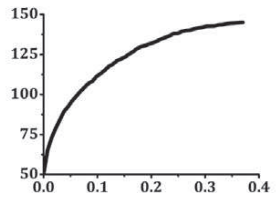 & 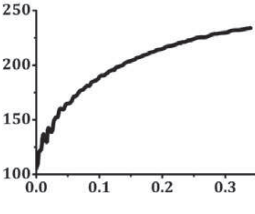 & 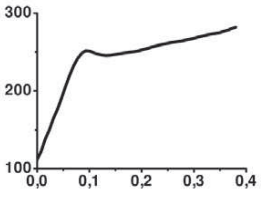 \\
\hline
\end{tabular}

Fig. 6. Various shapes of stress-strain curves of the $42 \mathrm{CrMo} 4-\mathrm{FP}$ steel as a function of thermomechanical conditions.

Table 1

Different formulations for the quasi-static stress-strain constitutive laws.

\begin{tabular}{lll}
\hline Reference & Formulation & Parameters \\
\hline Ludwik (1909) & $\sigma=\sigma_{0}+B \varepsilon^{n}$ & $\sigma_{0}, B, n$ \\
Hollomon (1945) & $\sigma=\sigma_{0} \varepsilon^{n}$ & $\sigma_{0}, n$ \\
Prager (1955) & $\sigma=\sigma_{0}+\tanh \left(\frac{E \varepsilon}{\sigma_{0}}\right)$ & $\sigma_{0}, E$ \\
Voce (1948) & $\sigma=\sigma_{s}+\left(\sigma_{0}-\sigma_{s}\right) \exp \left(\frac{-\varepsilon}{\varepsilon_{0}}\right)$ & $\sigma_{0}, \sigma_{s}, \varepsilon_{0}$ \\
Swift (1952) & $\sigma=\sigma_{0}\left(\varepsilon+\varepsilon_{0}\right)^{n}$ & $\sigma_{0}, \varepsilon_{0}, n$ \\
\hline
\end{tabular}

These models are referred to as decoupled constitutive equations because there is no coupling between the effects of hardening, temperature sensitivity and strain rate sensitivity. Among the models most used to simulate manufacturing processes in industry and for research purposes: Sellars (1985) model, Picart (1986) model and Johnson and Cook (1983) model can be cited. In particular, the Johnson and Cook (1983) model has been widely used to simulate relatively rapid processes such as machining and forging. This model is expressed by: 
Table 2

List of multiplicative functions describing the effect of strain rate and temperature.

\begin{tabular}{|c|c|c|c|}
\hline \multicolumn{2}{|l|}{$\sigma_{\dot{\varepsilon}}$ function } & \multicolumn{2}{|l|}{$\sigma_{T}$ function } \\
\hline Power law & $\dot{\varepsilon}^{m}$ & Power law & $T^{-m}$ \\
\hline Cowper and Symonds (1957) & $1+\left(\frac{\dot{\varepsilon}}{\dot{\varepsilon}_{0}}\right)^{m}$ & Johnson and Cook (1983) & $1-\left(\frac{T-T_{0}}{T_{m}-T_{0}}\right)^{m}$ \\
\hline Ludwik (1909) & $\log \left(\frac{\dot{\varepsilon}}{\dot{\varepsilon}_{0}}\right)$ & Litonsky (1977) & $1-\frac{T}{T_{0}}$ \\
\hline Sokolowsky (1948) & $\log \left(1+\frac{\dot{\varepsilon}}{\dot{\varepsilon}_{0}}\right)$ & Vinh et al. (1980) & $\exp \left(\frac{W}{T}\right)$ \\
\hline \multirow[t]{2}{*}{ Johnson and Cook (1983) } & $1+C \ln \left(\frac{\dot{\varepsilon}}{\dot{\varepsilon}_{0}}\right)$ & Zhao and Gary (1996) & $1-B\left(T-T_{0}\right)$ \\
\hline & & Arrhenius & $\exp \left(\frac{-Q}{R T}\right)$ \\
\hline
\end{tabular}

$\sigma_{J C}=\left[A+B \varepsilon^{n}\right]\left[1+C \ln \left(\frac{\dot{\varepsilon}}{\dot{\varepsilon}_{0}}\right)\right]\left[1-\left(\frac{T-T_{0}}{T_{m}-T_{0}}\right)^{m}\right]$

where $T_{m}$ is the melting temperature of the material, $T_{0}$ and $\dot{\varepsilon}_{0}$ are the reference temperature and strain rate. Many authors have modified this formulation to better represent certain phenomena or specific applications. For instance, Holmquist and Johnson (1991) experimentally observed an increase in the stress with a large strain rate greater than that given by expression (3). Andrade et al. (1994) have empirically modified the temperature term to represent the effect of softening due to dynamic recrystallization when the temperature exceeds a limit value $T_{c}$.

\subsection{Coupled models}

The decoupling between hardening, strain rate and temperature is a strong assumption in terms of constitutive modelling. This decoupling implies that the shape of the stress-strain curve does not change after a variation in strain rate or temperature. Several authors have shown the limits of these models. They found that the softening phenomenon is essential for the initiation and amplification of strain localization, which is the cause of the formation of adiabatic shear bands in the simulation of machining operations. Two types of modification to the decoupled empirical models have been proposed: the first consists of introducing a coupling between the three terms (strain hardening, temperature sensitivity and strain rate sensitivity). However the final expression remains multiplicative (Khan and Liang, 1999; Liang and Khan, 1999; Calamaz et al., 2010; Bäker, 2006). The second category of coupled phenomenological models considers a quasi-static model (Table 1) and transforms its constants into internal variables that are functions of temperature and strain rate. Several authors have chosen the Voce (1948) law which tends to a saturation stress $\sigma_{s}$ with increasing strain. For instance, Lurdos (2008) added a supplementary term $A \varepsilon^{n}$ to better model the stress observed in certain cases (Table 3(B1)). The five parameters $\sigma_{0}, \sigma_{s}, r, A$, and $n$ (denoted $\beta_{i}$ ) vary with temperature and strain rate. They are expressed as a function of the Zener-Holloman parameter $Z=\dot{\varepsilon} \exp \left(\frac{Q}{R T}\right)$ (Zener and Holloman, 1944) connecting the temperature to the strain rate $(Q$ is the apparent activation energy of the material and $R=8.314 \times 10^{-3} \mathrm{~kJ} \mathrm{~mol}^{-1} \mathrm{~K}^{-1}$ is the universal ideal gas constant).

Finally, these models assume the convergence of the flow stress to a saturation state. Their identification requires that this state be achieved experimentally. Montheillet (1996) showed that for materials with high stacking fault energy, very high amounts of deformation $(\varepsilon \approx 50)$ are required to reach the saturation state. This saturation state is generally predicted by extrapolation of the experimental stress-strain curves during the identification process. This constitutes a weakness of this type of phenomenological formulation. For these reasons, the model proposed in this work falls into the first category of empirical coupled laws. The aim is to improve the cost/accuracy ratio, that is, to propose a model that reproduces as faithfully as possible the experimental phenomena while keeping the number of model parameters to a minimum.

\subsection{Proposed phenomenological coupled model}

Drawing on the conclusions from the experimental study on the three steels investigated (Hor et al., 2013), two different couplings are proposed in this model. The first involves coupling between the effects of work hardening and temperature. The second coupling is between the effects of strain rate and temperature. This proposition comes from the classification of the complete deformation domain into three sub-domains: cold, semi-hot and hot deformation. This classification highlights the fact that different behaviour was observed in each domain, especially concerning the viscosity.

(i) Modelling the competition between work hardening and softening. The competition between strain hardening and softening is the origin of the variation in the slope of the stress-strain curve from one temperature to another. Empirical modelling of this competition requires a combination of two terms. This combination can be a simple addition of two functions: a work hardening function and a softening function (Hor, 2011) or it can have a multiplicative form as per the TANH model (Calamaz et al., 2010). The first term is physically more justifiable but is very difficult to identify. In fact, additive laws are strongly coupled and do not allow the elimination of terms in order to identify another term independently. The second term is more phenomenological, but it has the advantage of greater ease of identification. For these reasons, the second form was chosen here to model the hardening-softening competition. The expression of the function $D$ (Table $4(\mathrm{i})$ ) has been simplified, by reducing the number of parameters, compared to the TANH model (Table 3(A3)). 
Table 3

Different formulations of coupled constitutive equations.

\begin{tabular}{ll}
\hline Reference & Formulation \\
\hline $\begin{array}{c}\text { (A1) Khan and Liang } \\
\text { (1999) }\end{array}$ & $\sigma=\left[A+B\left(1-\frac{\ln \dot{\varepsilon}}{\ln \dot{\varepsilon}_{0}}\right) \varepsilon^{n}\right][\dot{\varepsilon}]^{C}\left[1-\left(\frac{T-T_{0}}{T_{m}-T_{0}}\right)^{m}\right]$ \\
(A2) Bäker (2006) & $\sigma=\left[A \varepsilon^{n_{0} f(T)}\right]\left[1+C \ln \left(\frac{\dot{\varepsilon}}{\dot{\varepsilon}_{0}}\right)\right] f(T)$ \\
& with $f(T)=\exp \left[-\left(\frac{T}{T_{a}}\right)^{m}\right]$ \\
(A3) Calamaz et al. & $\sigma=\sigma_{J C}\left[D+(1-D) \tanh \left(\frac{1}{\varepsilon+\varepsilon_{a}}\right)\right]$ \\
(2010) & with $D=1-\left(\frac{p \varepsilon^{r}}{1+p \varepsilon^{r}}\right) \tanh \left[\left(\frac{T-T_{0}}{T_{\text {rec }}-T_{0}}\right)^{q}\right]$ \\
& \\
(B1) Lurdos (2008) & $\sigma=\sigma_{s}+\left(\sigma_{0}-\sigma_{s}+A \varepsilon^{n}\right) \exp (-r \varepsilon)$ \\
& with $\beta_{i}=\beta_{i}^{0} Z^{m_{i}}, \beta_{i}=\sigma_{0}, \sigma_{s}, r, A, n$ \\
(B2) Mulyadi et al. & $\sigma=K \lambda Z^{m}(1-\exp (-\beta \varepsilon))$ \\
(2006) & with $\lambda=\lambda_{s}+\left(1-\lambda_{s}\right) \exp (-\alpha \varepsilon)$ and \\
& $\lambda_{s}=\lambda_{0} Z^{q}$ \\
\hline
\end{tabular}

(ii) Modelling the temperature sensitivity. The sensitivity of the stress to the temperature is almost independent of the strain rate. It has been shown that a temperature variation has the same effect on the stress at different strain rates (Hor et al., 2013). A strain rate variation does not affect the sensitivity of the stress to the temperature in the case of the three steels studied. From this finding and for reasons of simplicity, the temperature dependence can be introduced in a similar manner to that proposed by Johnson-Cook. A slight improvement was made in the proposed formulation (Table 4(ii)): a second parameter was added to better approximate this temperature sensitivity (Fig. 7).

(iii) Modelling the strain rate sensitivity. The experimental study conducted by Hor et al. (2013) on three steels shows that this dependence varies with temperature. Indeed, for low temperatures, the stress is almost insensitive to the strain rate. As the temperature increases, the material becomes more viscous and the stress becomes more dependent on the strain rate (see Fig. 3). The identification of the Johnson-Cook model based on experimental data leads to different values of the parameter $C$ (denoted $C_{i}$ ) according to the considered temperatures (Fig. 8(a)). To model this variable dependence, the Johnson-Cook formulation was modified by replacing the parameter $C$ by a function $C(T)$ which depends on the temperature (Fig. 8(b)). The expression $C(T)$ (Table 4(iii)) has been proposed based on experimental observations.

Table 4

Formulation of the proposed coupled constitutive law.

\begin{tabular}{ll}
\hline$\sigma=\sigma_{\varepsilon}(\varepsilon, T) . \sigma_{T}(T) . \sigma_{\dot{\varepsilon}}(\dot{\varepsilon}, T)$ & \\
\hline (i) & $\sigma_{\varepsilon}(\varepsilon, T)=\left[A+B \varepsilon^{n}\right]\left[D+(1-D) \tanh \left(\frac{1}{\varepsilon+\varepsilon_{a}}\right)\right]$ \\
& with $D=1-\left(\frac{p \varepsilon}{1+p \varepsilon}\right) \tanh \left(\frac{T-T_{0}}{T_{\text {rec }}-T_{0}}\right)$ \\
(ii) & $\sigma_{T}(T)=1-m_{1}\left(\frac{T-T_{0}}{T_{m}-T_{0}}\right)^{m_{2}}$ \\
(iii) & $\sigma_{\dot{\varepsilon}}(\dot{\varepsilon}, T)=1+C(T) \ln \left(\frac{\dot{\varepsilon}}{\dot{\varepsilon}_{0}}\right)$ \\
& with $C(T)=\frac{C_{1} \exp \left(C_{2} \frac{T}{T_{m}}\right)}{\frac{T}{T_{m}}}$ \\
&
\end{tabular}

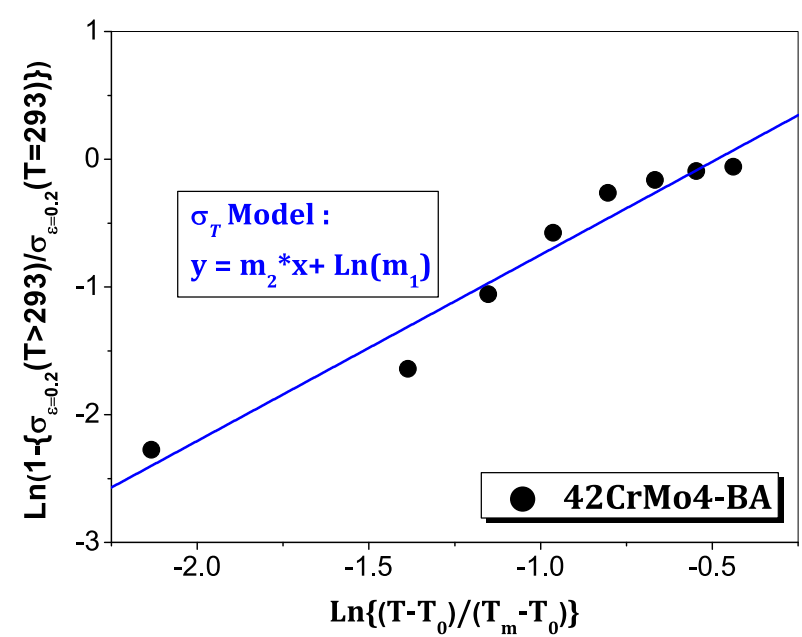

Fig. 7. Identification of the parameters $m_{1}$ and $m_{2}$ from experimental database for the 42CrMo4-BA steel.

\section{Identification and comparison of the different models}

Initially, compression tests were used to identify the various models presented in Table 5 . The identified parameters are valid for a strain range between 0 and 0.5 , temperatures between 293 and $1273 \mathrm{~K}$, and for strain rates between $10^{-2}$ and $10^{4} \mathrm{~s}^{-1}$. The experimental stress-stain curves are sometimes extrapolated in order to estimate the saturation stress, necessary for the determination of some models. To facilitate the comparison, all models were identified from the same experimental database, even though some of them do not require such an extensive database. The sensitivity of the Johnson-Cook model parameters to the identification procedure and the loading modes will be discussed. To do so, shear tests and a minimum number of compression tests were used to identify the model.

In addition to the model parameters shown in Table 5, the models include certain coefficients that define the range of validity of the model (the reference temperature $T_{0}$ and reference strain rate $\dot{\varepsilon}_{0}$ ), define certain phenomena (i.e. the softening onset temperature $T_{\text {rec }}$ ) or intrinsic properties of the material (i.e. the melting temperature $T_{m}$ and the apparent activation energy $Q$ ). These parameters are given for the three steels studied in Table 6 .

\subsection{Identification of the different models}

An optimization program based on the Levenberg-Marquardt method (Marquardt, 1963) (derived from Newton's method) was used for the identification. This method required the introduction of a set of initial parameters which are of the same order of magnitude as the final parameters. To resolve this problem, a method of normalizing the parameters (between 0 and 1) was used. For some cases a combination of the Simplex method and the Levenberg-Marquardt method was used to obtain the optimal set of parameters (i.e. the parameters minimizing the squared variation between the model and the experimental results). The uniqueness of the solution was verified 
(a)

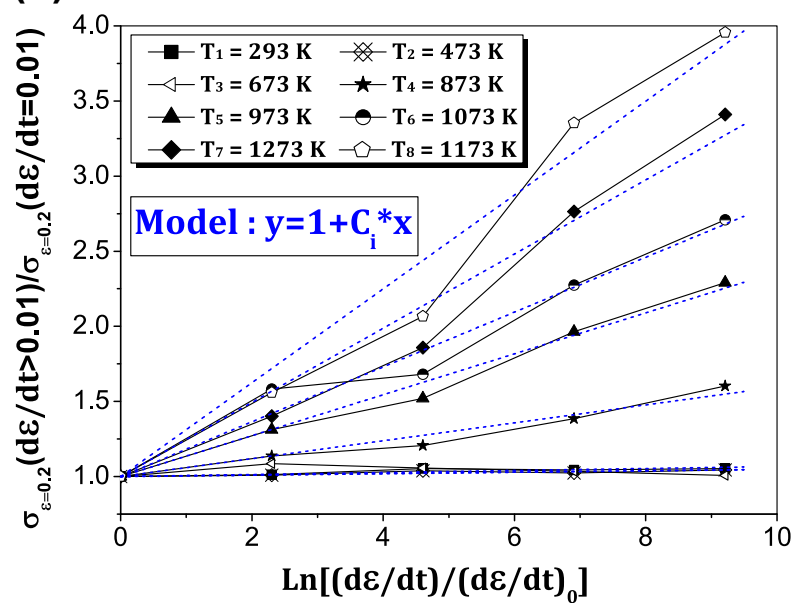

(b)

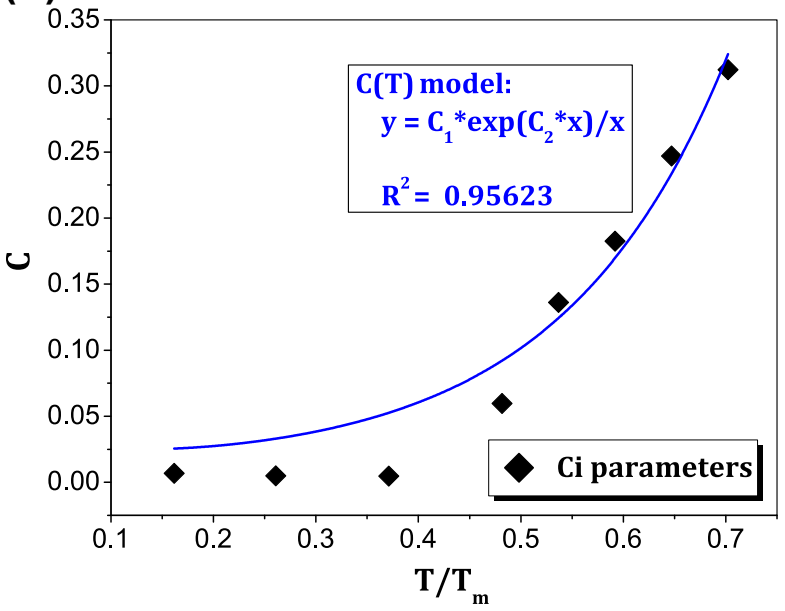

Fig. 8. (a) Identification of the various parameters $C_{i}$ related to different temperatures $T_{i}$ and (b) correlation between the function $C(T)$ and the parameters $C_{i}$, for the 42CrMo4-BA steel.

by checking if the same optimum parameter set was obtained when the initial values were varied. Sensitivity analyses were also performed for some models (e.g. the TANH model) to determine the influence of each parameter (Hor, 2011).

The least squares method was used for identification. The objective function was:

$$
\begin{aligned}
S\left(\beta_{j}\right) & =\sum_{k=1}^{N} a_{k} s_{k}\left(\beta_{j}\right) \\
& =\sum_{k=1}^{N}\left[a_{k} \sum_{i=1}^{200}\left\{\left(\sigma_{\text {exp }}^{i}\right)_{k}-L\left(\dot{\varepsilon}_{k}^{i}, \dot{\varepsilon_{k}}, T_{k}, \beta_{j}\right)\right\}^{2}\right]
\end{aligned}
$$

The quantity $L\left(\varepsilon_{k}^{i}, \dot{\varepsilon}_{k}, T_{k}, \beta_{j}\right)$ was calculated from the analytical expression of the constitutive model for compression loading, or given by the FE model for shear loading. In this case, it was the efforts and displacements that were evaluated and not the stresses and strains.

$N$ is the number of experimental tests (number of thermomechanical conditions) used for the identification, $a_{k}$ is the weighting coefficients to allow favored one condition over another. ( $a_{k}$ is always equal to 1 in our case). The $\beta_{j}$ are the model parameters to identify. A step of smoothing and interpolation was executed to obtain only 200 points for each curve. Self-heating effect was taken into account for some thermomechanical conditions. In fact:

Table 5

List of models investigated and the associated parameters to be identified.

\begin{tabular}{lcl}
\hline Model & $\begin{array}{c}\text { Number of } \\
\text { parameters }\end{array}$ & Parameters to be identified \\
\hline $\begin{array}{c}\text { Johnoson- } \\
\text { Cook }\end{array}$ & 5 & $A, B, n, C, m$ \\
$\begin{array}{c}\text { Bäker } \\
\text { TANH }\end{array}$ & 5 & $A, T_{a}, n_{0}, C, m$ \\
Lurdos & 9 & $A, B, n, C, m, p, q, r, \varepsilon_{a}$ \\
Proposed & 9 & $m_{0}, m_{s}, m_{r}, m_{A}, m_{n}, \sigma_{0}^{0}, \sigma_{s}^{0}, r^{0}, A^{0}, n^{0}$ \\
model & & $A, B, n, p, \varepsilon_{0}, C_{1}, C_{2}, m_{1}, m_{2}$ \\
\hline
\end{tabular}

Table 6

Values of the constants used in the different models for the three steels investigated.

\begin{tabular}{llllll}
\hline Material & $\dot{\varepsilon}_{0}\left(\mathrm{~s}^{-1}\right)$ & $T_{0}(\mathrm{~K})$ & $T_{\text {rec }}(\mathrm{K})$ & $T_{m}(\mathrm{~K})$ & $Q\left(\mathrm{~kJ} \mathrm{~mol}^{-1}\right)$ \\
\hline 42CRMo4-FP & 0.01 & 293 & 673 & 1813 & 300 \\
42CRMo4-BA & 0.01 & 293 & 673 & 1813 & 300 \\
100Cr6-FP & 0.01 & 293 & 673 & 1760 & 300 \\
\hline
\end{tabular}

- For compression tests, at cold deformation, for the strain rates less than $102 \mathrm{~s}^{-1}$, we have seen that compression did not have much effect in the case of the materials studied (Note 1 ). When the strain rate became greater than or equal to $102 \mathrm{~s}^{-1}$, a correction was performed by using the FE simulations. The Johnson-Cook constitutive law was readjusted to find the same experimental curve as an adiabatic calculation. Then, a second isothermal calculation was made using the same material parameters. The newly corrected experimental curve was that obtained by the isothermal calculation (Fig. 9). This procedure is rather heavy to implement. In addition, during tests on semi-hot and hot deformation domain, we did not observe a significant increase in temperature due to self-heating due to the feedback system. Disturbances (of a few degrees) were only observed. Thus the self-heating effects were neglected at hot deformation.

- For shear tests, the self-heating problem was considered in numerical simulation because the identification was performed based on a FE model (with an adiabatic calculation) due to the heterogeneity of the deformation.

The Johnoson-Cook model. This model was identified using the complete experimental database. The Levenberg-Marquardt optimization algorithm was used. The five parameters were identified simultaneously.

The Bäker model. The number of parameters in this model was the same as the Johnson-Cook model. The identification of this model, for the three steels, was performed 
in the same way as the Johnson-Cook model. The identified parameters are given in Table 8 .

The TANH model. According to Calamaz et al. (2010), the advantage of this model is that the Johnson-Cook parameters, previously identified, can be used. Only five additional parameters, added to take softening into account, led to be identified. The value of $T_{\text {rec }}$ (defined as the softening onset temperature) was determined directly from the experimental curves. Finally, using the same optimization algorithm, the model parameters are shown in Table 9.

The Lurdos model. The identification was carried out in two steps. Firstly, the stress-strain curves for different thermo-mechanical conditions were approximated by the equation:

$\sigma=\sigma_{s}+\left(\sigma_{0}-\sigma_{s}+A \varepsilon^{n}\right) \exp (-r \varepsilon)$

An example of this approximation, as well as the evolution of the parameters $\sigma_{s}$ and $\sigma_{0}$, for the 42CrMo4-FP steel, is given in Fig. 10.

The second step was to use the values of $\sigma_{s}, \sigma_{0}, r, A$, and $n$, determined for the different conditions in order to calculate the parameters of the equations $\beta_{i}=\beta_{i}^{0} Z^{m_{i}}$. After determining the values of the Zener-Holloman parameters $Z$ for the various tests, the variables $\sigma_{s}, \sigma_{0}, r, A$ and $n$ were then plotted as a function of $Z$ in a logarithmic diagram. An example is given in Fig. 11 which shows the value of the parameters $\sigma_{s}$ and $\sigma_{0}$.

For the three steels studied, two different behaviours could be distinguished depending on the value of $Z$. Indeed, for the six variables $\left(\sigma_{s}, \sigma_{0}, r, A\right.$, and $\left.n\right)$, the linear regression changed slope at a value of $\ln (Z) \approx 45$ (Fig. 11). This value marked the separation between the cold deformation, semi-hot deformation $\left(T / T_{f} \leqslant 0.5\right)$ and hot deformation $\left(T / T_{f} \geqslant 0.5\right)$ domains. The parameters of the Lurdos model are given for $\ln (Z) \leqslant 45$ and for $\ln (Z)>45$. Table 10 summarises all the model parameters. The parameters $\sigma_{0}^{0}, \sigma_{s}^{0}$ and $A_{0}$ are expressed in MPa and the other parameters are dimensionless.

The proposed model. The simultaneous identification of nine parameters using the previously discussed optimization algorithm poses certain problems in terms of unique-

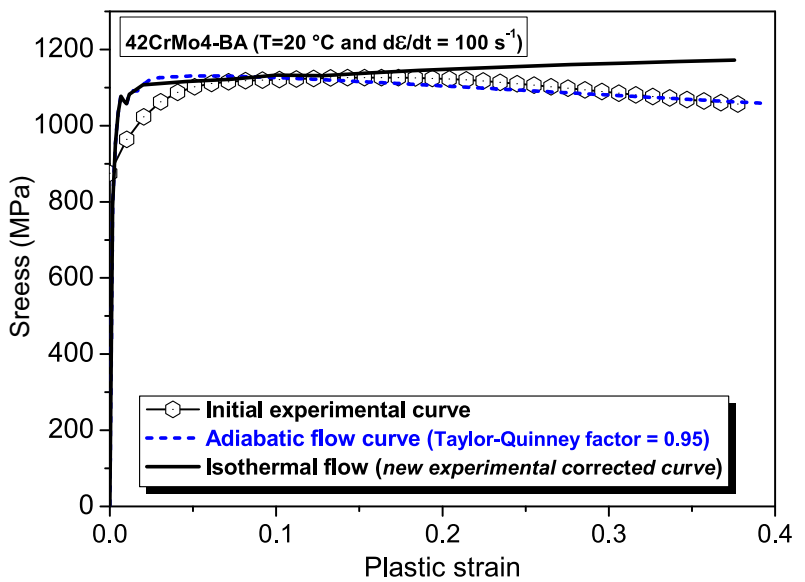

Fig. 9. Comparison between the initial experimental curve, the curve obtained by $\mathrm{FE}$ simulation using an adiabatic flow and using an isothermal flow, for the 42CrMo4-BA steel. ness of the solution, that is the solution depends on the initial parameter set. Hence, a simple identification procedure has been proposed. It consists of four steps: (1) identify the parameters $m_{1}$ and $m_{2}$ at the reference strain rate $\dot{\varepsilon}_{0}$, (2) identify the function $C(T)$ and its parameters $C_{1}$ and $C_{2}$, (3) determine the hardening parameters $\left(A=\sigma_{0}\right.$, $B$ and $n$ ) by assuming that during the reference test (i.e. at the lowest strain rate and temperature) softening is negligible, and (4) identify the softening parameters ( $p$ and $\varepsilon_{0}$ ). The resulting model parameters are given in Table 11 .

At this point, it can be concluded that the increase in the number of model parameters increases the number of experimental tests necessary for the identification but not necessarily the difficulty of the identification. The latter is related to the degree of coupling between the various phenomena represented by the model and the mathematical formulation of the coupling. In the literature, the "cost" of a model is often related to the number of parameters which increases the number of tests needed for the identification. Other difficulties encountered during the identification, such as achieving the saturation state and the mathematical impossibility of decoupling certain physical phenomena (e.g. additive laws (Zerilli and Armstrong, 1987) should be considered in this criterion.

\subsection{Sensitivity of the model parameters to the identification method and the loading type}

In the literature, it is common to find very different values for the parameters of a constitutive equation for the same material. In particular, several contradictions have been noted for the Johnson-Cook model (Tounsi et al., 2002; Huang and Liang, 2003; Guo et al., 2006). In order to study the influence of the numerical artifact causing this dispersion, the Johnson-Cook model was first identified using the compression tests with two different identification methods. The first method (method 1 in Table 12) is a sequential approach. It consisted of eliminating the terms $\sigma_{T}$ and $\sigma_{\dot{\varepsilon}}$ of Eq. 3 (by using tests at $T=T_{0}$ and $\dot{\varepsilon}=\dot{\varepsilon}_{0}$ ) to identify the hardening parameters $(A, B$ and $n)$. Then eliminate only the term $\sigma_{\dot{\varepsilon}}$ by using tests at $\dot{\varepsilon}=\dot{\varepsilon}_{0}$ ) and identify the parameter $m$, and finally identify $C$. This method used only a part of the experimental database. The second method (method 2 in Table 12) used an optimization algorithm to determine the optimal parameters and minimize the difference between the models and experimental results.

Moreover, using an inverse approach based on a finite element model of the hat-shaped specimens coupled with an optimization algorithm (see Fig. 5(b)), the five parameters of the Johnson-Cook constitutive equation that mini-

Table 7

Parameters of the Johnson-Cook model identified using compression tests for the three steels investigated.

\begin{tabular}{llllll}
\hline Material & $A(\mathrm{MPa})$ & $B(\mathrm{MPa})$ & $n$ & $C$ & $m$ \\
\hline 42CrMo4-FP & 504 & 370 & 0.170 & 0.025 & 0.793 \\
42CrMo4-BA & 622 & 429 & 0.083 & 0.011 & 0.668 \\
100Cr6-FP & 594 & 359 & 0.059 & 0.003 & 0.718 \\
\hline
\end{tabular}


Table 8

Parameters of the Bäker model identified for the three steels investigated.

\begin{tabular}{lrllrl}
\hline Material & $A(\mathrm{MPa})$ & $n_{0}$ & \multicolumn{1}{l}{$\mathrm{C}$} & \multicolumn{1}{c}{$T_{0}(\mathrm{~K})$} & \multicolumn{1}{l}{$m$} \\
\hline 42CrMo4-FP & 838 & 0.067 & 0.025 & 1039 & 4.005 \\
42CrMo4-BA & 1097 & 0.032 & 0.012 & 968 & 3.487 \\
100Cr6-FP & 918 & 0.020 & 0.005 & 963 & 3.186 \\
\hline
\end{tabular}

mized the difference between calculated and experimental force for different thermomechanical conditions were deteremined (method 3 in Table 12). In this case, the loading type studied is shear, with the aim of analysing the effect of the loading type on the dispersion of the JohnsonCook parameters.

The values of the Johnson-Cook parameters obtained by the three methods are different. The $B$ and $n$ parameters obtained from the shear tests are close to those obtained using the compression tests and the second identification method. This shows that the hardening is almost the same for both loadings. This result seems logical given that the two numerical methods of identification are almost identical. They were based on an optimization algorithm that minimized the difference between all the experimental curves and the results from an analytical model (for the compression tests) or via a finite element model (for the shear tests). These two methods used the complete experimental database in contrast to the first method where only few tests were used in the identification procedure.

However, the parameter $m$ (controlling the temperature sensitivity) was higher for the shear loading condition. That is, the flow stress is more sensitive to the temperature when the material is loaded in shear. The choice of the loading mode for the identification of the constitutive law must therefore be consistent with the dominating loading mode of the forming process being studied. For example, the machining process can be characterized by

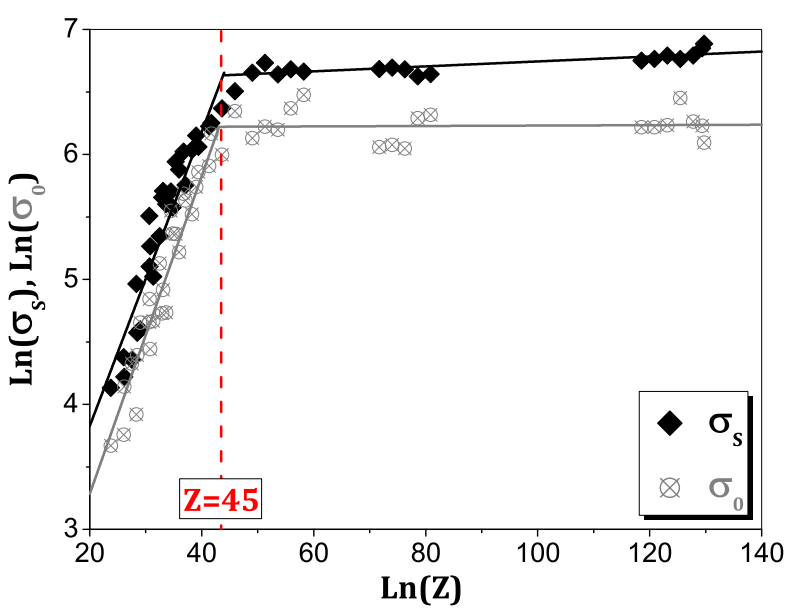

Fig. 11. Experimental values and linear regression parameters $\left(\sigma_{s}\right.$ and $\left.\sigma_{0}\right)$ for the Lurdos model for the 42CrMo4-BA steel.

highly localized deformation in a shear loading path. For this process the most appropiate identification method would be to use the shear test data. This is referred to as being physical (or experimental) simulation of the process (Hor et al., 2013).

For both loading cases (compression and shear), the identified parameters were unique. In order to verify the uniqueness, the initial material parameters were varied usually and the program converged to the same parameters. However, the purpose of this paragraph was to show that when the size of the database, the type of loading or the identification method, were changed the set of parameters changes also, which explains the variability found in the literature for the same material. This was especially true when the model did not take into account all the observed phenomena (e.g. softening for the Johnson-Cook).

Table 9

Parameters of the TANH model identified using compression tests for the three steels investigated.

\begin{tabular}{lllllllll}
\hline Material & $A(\mathrm{MPa})$ & $B(\mathrm{MPa})$ & $n$ & $C$ & $m$ & $p$ & \multicolumn{1}{c}{$\varepsilon_{0}$} \\
\hline 42CrMo4-FP & 504 & 370 & 0.170 & 0.025 & 0.793 & 7.900 & 5 \\
42CrMo4-BA & 622 & 429 & 0.083 & 0.011 & 0.668 & 0.924 & 5 \\
100Cr6-FP & 594 & 359 & 0.059 & 0.003 & 0.718 & 5.103 & 5 \\
\hline
\end{tabular}

(a) Approximation example

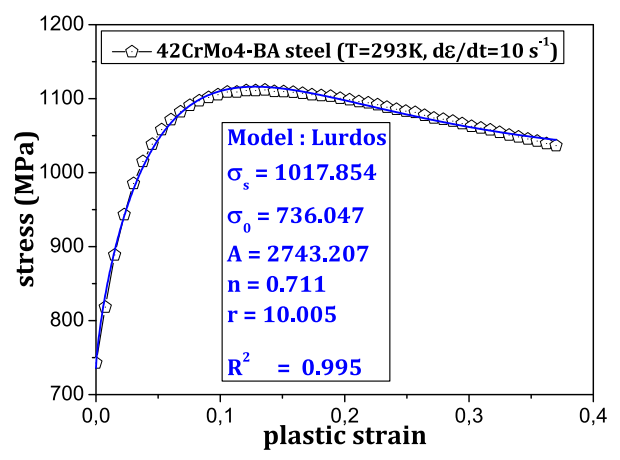

(b) Evolution of $\sigma_{s}$

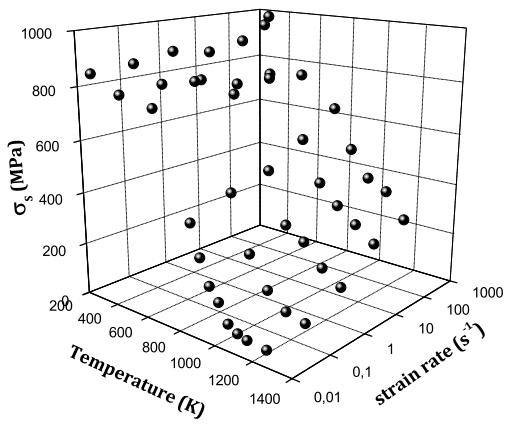

(c) Evolution of $\sigma_{0}$

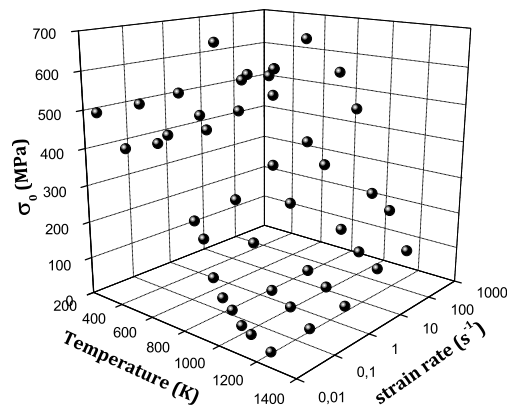

Fig. 10. Example of the evolution of the parameters $\sigma_{s}, \sigma_{0}, r, A$, and $n$ as a function of $T$ and $\dot{\varepsilon}-$ for the $42 \mathrm{CrMo} 4$-BA steel. 
Table 10

The parameters from the Lurdos and Montheillet model identified for the three steels investigated.

\begin{tabular}{|c|c|c|c|c|c|c|c|c|c|c|}
\hline Material & $\sigma_{0}^{0}$ & $\sigma_{s}^{0}$ & $r_{0}$ & $A_{0}$ & $n_{0}$ & $m_{0}$ & $m_{s}$ & $m_{r}$ & $m_{A}$ & $m_{n}$ \\
\hline \multicolumn{11}{|c|}{ For $\ln (Z) \leqslant 45$ or $T / T_{f} \geqslant 0.5$} \\
\hline 42CrMo4-FP & 2.1 & 4.3 & 0.433 & 4.7 & 0.72 & 0.127 & 0.118 & 0.076 & 0.124 & -0.007 \\
\hline 42CrMo4-BA & 1.3 & 6.3 & 4.461 & 30.1 & 0.573 & 0.142 & 0.105 & 0.007 & 0.054 & -0.003 \\
\hline 100Cr6-FP & 2.3 & 5.5 & 3.399 & 8.5 & 0.537 & 0.121 & 0.105 & 0.015 & 0.094 & -0.006 \\
\hline \multicolumn{11}{|c|}{ For $\ln (Z)>45$ or $T / T_{f} \leqslant 0.5$} \\
\hline 42CrMo4-FP & 499 & 696 & 2.986 & 462 & 0.329 & 0.001 & 0.002 & 0.014 & 0.001 & 0.001 \\
\hline 42CrMo4-BA & 534 & 781 & 17.5 & 215 & 0.242 & 0.002 & 0.002 & -0.005 & 0.013 & 0.004 \\
\hline 100Cr6-FP & 498 & 656 & 2.344 & 219 & 0.133 & 0.002 & 0.003 & 0.012 & 0.014 & 0.009 \\
\hline
\end{tabular}

Table 11

Hardening and softening parameters identified for the three steels investigated.

\begin{tabular}{lllllllll}
\hline Material & $A(\mathrm{MPa})$ & $B(\mathrm{MPa})$ & $n$ & $p$ & $\varepsilon_{0}$ & $C_{1}$ & $m_{2}$ \\
\hline 42CrMo4-FP & 505 & 449 & 0.186 & 7.900 & 0.547 & $1.2 \times 10^{-3}$ & 7.42 \\
42CrMo4-BA & 622 & 584 & 0.175 & 0.924 & 2.915 & $1.9 \times 10^{-4}$ & 1.61 \\
100Cr6-FP & 600 & 318 & 0.109 & 5.103 & 0.674 & $8.7 \times 10^{-4}$ & 7.67 \\
\hline
\end{tabular}

\subsection{Comparison between the different constitutive models}

Some predictions of the models identified in the previous paragraph, are presented below in the same stressstrain diagram for several thermomechanical conditions and the three domains of deformation (see Fig. 12). In general, the difference between the model predictions and experimental results was very large for the Johnson-Cook, the Bäker and the TANH constitutive laws. The stressstrain curves from the proposed model and the Lurdos model were always closer to the experimental curves for the three steels investigated. The proposed model performed better than the Lurdos model in the semi-hot domain. In the cold domain, the Lurdos model was more accurate, especially at high strain rate causing a decrease in strain hardening because it uses a formulation includes saturation whereas the proposed model is based on a power law. In the hot domain, the two models gave comparable results. The proposed model showed a tendency for the stress-strain curve to decrease in this domain although the experimental trend is the opposite.

In order to quantify the difference between the predicted and experimental curves, a relative error was defined as the ratio of the area between the two curves to the area under the experimental curve. For test $i$, the relative error $E_{i}$ is given by:

$E_{i}=\frac{\int_{0}^{\varepsilon_{f}}\left|\left(\sigma_{\text {exper }}\right)_{i}-\left(\sigma_{\text {model }}\right)_{i}\right| d \varepsilon}{\int_{0}^{\varepsilon_{f}}\left(\sigma_{\text {exper }}\right)_{i} d \varepsilon}$
The average relative error between the model predictions and the $N$ experimental curves performed for a given material is therefore:

$E_{m}=\frac{\sum_{i=1}^{N} E_{i}}{N}$

Fig. 13 represents the average relative error for the five constitutive models and the three steels investigated: the 42CrMo4-FP steel, the 42CrMo4-BA steel and the 100Cr6FP steel. For these three materials, the error for the Johnson-Cook, Bäker and TANH models was between $10 \%$ and $25 \%$. However, for the Lurdos model and the proposed model the error was less than $10 \%$ for all three material. Despite the fact that the Lurdos model was identified in a piecewise manner (depending on the value of $Z$ ) which improved its capability, the proposed constitutive model was more accurate for the 42CrMo4-FP and 100Cr6-FP steels.

Furthermore, for all of the models, the average relative errors were lower for the 42CrMo4-FP steel. They were greater for the $42 \mathrm{CrMo} 4-\mathrm{BA}$ and $100 \mathrm{Cr} 6-\mathrm{FP}$ steel. This is due to the number of thermomechanical conditions used for identification. For the 42CrMo4-FP steel, experimental data for 45 different thermomechanical conditions were available. For the 100Cr6-FP steel only 33 different conditions were available and 25 conditions for the 42CrMo4BA steel. Hence, it can be concluded that increasing the number of experimental tests used for the identification process improves the accuracy of the constitutive model. It was also shown that the choice of these conditions can improve the accuracy of the model in some deformation

Table 12

Values of the Johnson-Cook parameters identified using the compression tests results by the two direct identification methods and using the shear tests by the inverse method. For the 42CrMo4-BA steel.

\begin{tabular}{lllll}
\hline Loading type (method) & $A(\mathrm{MPa})$ & $B(\mathrm{MPa})$ & $n$ & \multicolumn{1}{c}{${ }^{2}$} \\
\hline Compression (method 1) & 622 & 584 & 0.175 & 0.009 \\
Compression (method 2) & 622 & 429 & 0.083 & 0.011 \\
Shear (method 3) & 668 & 478 & 0.09 & 0.012 \\
\hline
\end{tabular}


domains (i.e. cold, semi-hot or hot) (Hor, 2011). Indeed, if more experimental data is used in the identification which belongs to for example the semi-hot deformation domain, the identified model will be more accurate in that domain. This can be reproduced numerically by adding weight factors to several tests to make the model more accurate for these tests.

\subsection{Summary}

The stress-strain constitutive models investigated in this work belong to the family of phenomenological or empirical models. The Johnson-Cook model represents the group of uncoupled empirical models. These models typically have a low number of parameters. There is no coupling between the effects of strain hardening/softening, strain rate and temperature. Decoupling simplified the identification of these models and reduced the number of experimental tests needed for the identification. These models could not predict the experimentally observed behaviour for the three steels. Even though they do not represent reality, these models are widely used in the literature for the numerical simulation of forming processes.

Other investigations have shown the limitations of these models particularly for the simulation of machining operations (Calamaz et al., 2010). Certain studies have shown that these models are unable to provide acceptable results, even qualitatively, for example to predict the chip shape during a machining operation. Following this work, several authors have introduced a coupling between the effects of strain hardening/softening, strain rate and temperature. This has been added in two different ways. First, by modifying the existing models. This group of models is represented in this work by the Bäker and TANH models which are an improvement compared to the Johnson-Cook law. Second, is to propose formulations based on simple

(a) 42CrMo4-FP steel
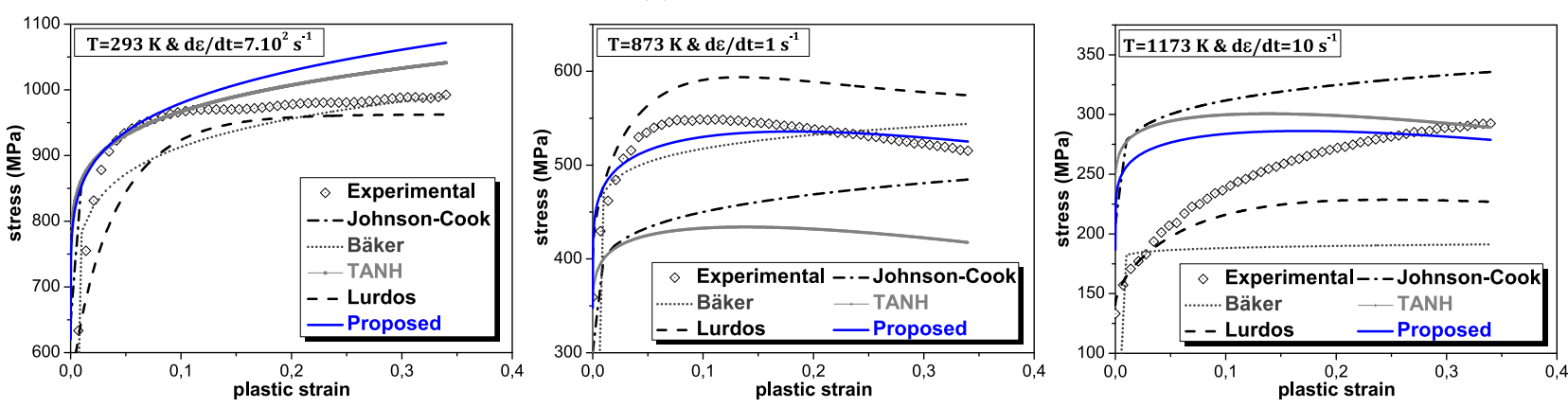

(b) 42CrMo4-BA steel
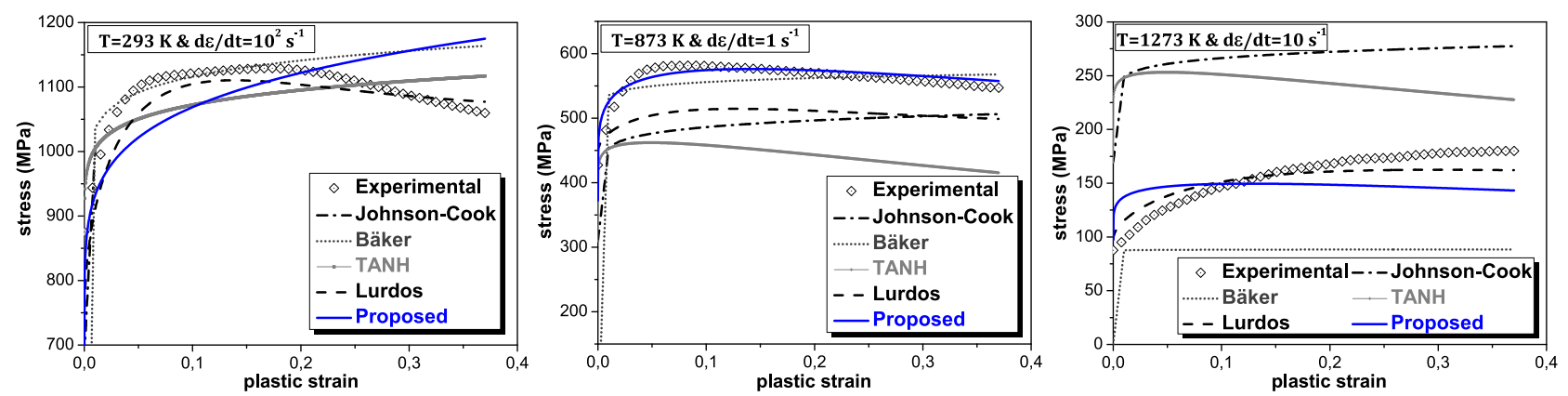

(c) 100Cr6-FP steel
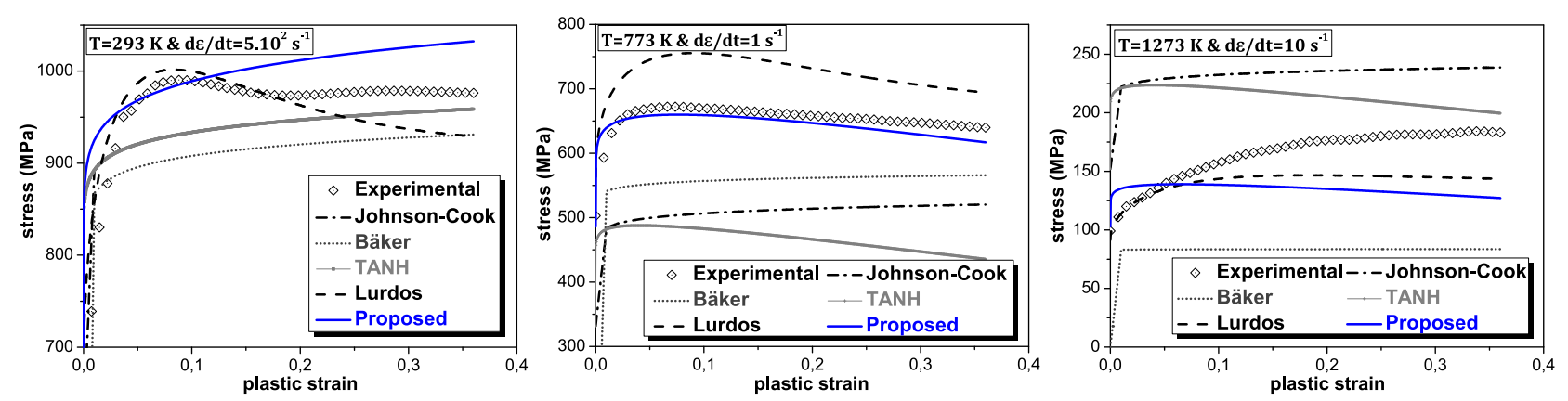

Fig. 12. Comparison between the different constitutive models for different thermomechanical conditions for the three steels investigated: (a) 42CrMo4-FP, (b) 42CrMo4-BA and (c) 100Cr6-FP. 
strain hardening constitutive modes (such as the Voce law) in which the parameters are transformed into internal variables. These variables are then assumed to evolve with temperature and strain rate. This category of models is represented here by the Lurdos model. Two types of coupling are used to take into account the influence of temperature and strain rate on the strain hardening.

Although, the number of parameters of Bäker model is not larger compared to Johnson-Cook model, the identification process is more complex. Bäker assumes that the appearance of softening is only a function of temperature. Its appearance diminishes the rate of strain hardening. This slope is always positive or zero. The results of this model are relatively inaccurate compared to the experimental observations. Small improvements can be seen compared to the Johnson-Cook law. The TANH model requires a higher number of experimental conditions for its identification. This model has four additional parameters compared to the Johnson-Cook law. It can reproduce reasonably well the competition between hardening and softening observed experimentally. However, the sensitivity of the flow stress to the rheological parameters is very different from the experimental results because it is identical to that proposed by Johnson-Cook. As for the Lurdos model, the identification procedure is simple but requires a vast experimental database. This is especially the case as the identification is done in a piecewise manner (depending on the value of $Z$ ), hence the need to have sufficient experimental data for each area. This model has ten parameters. It provides predictions that are close to the experimental results for the three steels.

The latter two models allow for strain softening via a competition mechanism between hardening and softening. The stress-strain curves can then be decreasing for certain thermomechanical conditions. In the Lurdos model, this softening is a function of temperature and strain rate, however in the TANH model only a temperature variation can cause the appearance of the softening phenomenon.

Finally, the proposed model gives more accurate predictions compared to those from the literature with a reason-

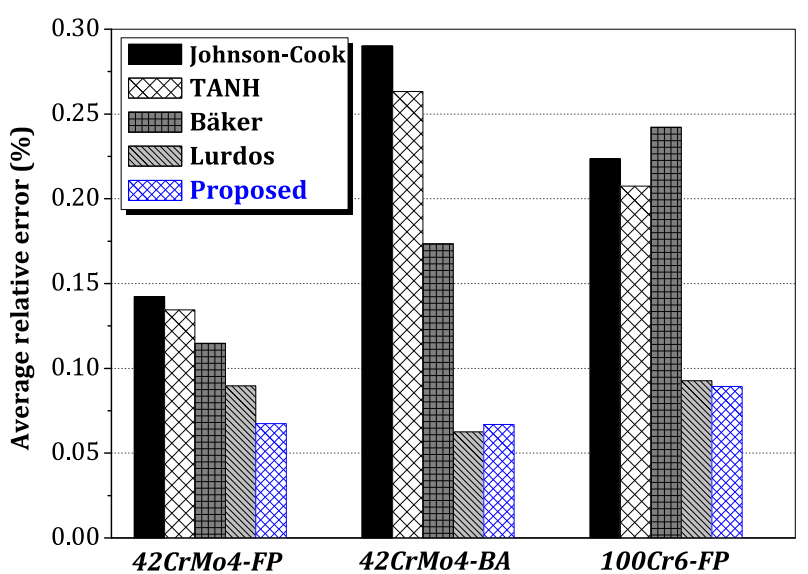

Fig. 13. Average relative error between the experimental results and the predictions of the different constitutive laws identified for the three steels investigated. The proposed model is shown in blue. (For interpretation of the references to colour in this figure legend, the reader is referred to the web version of this article.) able number of parameters (i.e. 9 parameters). It takes into account the phenomenon of softening accompanying plastic deformation at certain temperatures. The rate sensitivity depends on the temperature. Its identification is relatively easy but requires an extensive experimental database. It is also identifiable in a transitional regime and does not require the saturation stress to be achieved. It is therefore a good compromise between simplicity and accuracy, provided a sufficiently complete experimental database is available. The identification of the model for each domain, as per the Lurdos model, could further improve its accuracy even if this would increase the number of parameters and require more experimental testing.

\section{Validation of the different constitutive models for the simulation of orthogonal cutting}

To highlight the ability of the different constitutive models to take into account phenomena such as softening, a numerical simulation of a machining operation was done and compared to experimental results. This results consists on the cutting forces, temperature and chip shape formed during the machining of the 42CrMo4-BA steel. Different cutting conditions were investigated experimentally in this planar cutting configuration and compared to finite element simulations using different stress-strain constitutive equations.

\subsection{Experimental investigation of orthogonal cutting}

Orthogonal cutting (Merchant, 1945a,b) is a simplification of the machining problem, from both an experimental and a modelling point of view. Orthogonal cutting is a mechanical problem that occurs in a plane. If edge effects are neglected, this type of machining operation can be modelled in 2D. In this particular configuration, the three components of the cutting force usually encountered in three-dimensional cutting ( $\mathrm{Fa}, \mathrm{Fr}$ and $\mathrm{Ft}$ ) are reduced to two components ( $\mathrm{Fr}$ and $\mathrm{Ft}$ ), and the cutting depth is equal to the feed rate. A complete experimental set-up has been put in place in order to characterize the cutting process from a mechanical, thermal and metallurgical point of view as a function of the cutting parameters (cutting speed and feed rate). For this study, tests were only performed on the 42CrMo4-BA steel. Four cutting conditions were chosen for investigation. The cutting force, the temperature fields and the chip shape were investigated.

\subsubsection{Temperature field measurement by near-infra-red thermography}

In order to measure the temperature in the cutting zone a near-infra-red camera was used (M'Saoubi et al., 1998; Habak et al., 2007). As shown in Fig. 14, the thermographic images make it possible to determine the hottest point with respect to the cutting edge and to quantify the relative temperatures in the different shear zones, i.e. the primary shear zone observed on the cutting face (see the left most image in the column marked temperature field in Fig. 14), and the secondary and tertiary shear zones observed on the lateral face of the tool (see the right image 
in the column marked temperature field in Fig. 14). This thermal analysis showed precisely the evolution and position of the hot spot as a function of the cutting conditions. It was also observed that the temperature in the frictional zone with the tool increased when the feed rate or the cutting speed increased.

\subsubsection{Cutting forces}

The measurement of the cutting forces was done using a Kistler table dynamometer. This type of equipment is widely used in machining because of its sensitivity, accuracy and above all its high stiffness which does not disturb the machining operation (Habak et al., 2007). The different components ( $\mathrm{Fa}, \mathrm{Fr}$ and $\mathrm{Ft}$ ) of the global cutting force were accessible. The evolution of these forces as a function of time for different cutting conditions is given in the third column of Fig. 14. This force was very sensitive to the feed rate and the cutting speed. It increased when the feed rate increased and when the cutting speed decreased.

\subsubsection{Analysis of the chip shape}

Understanding the mechanisms involved in the machining process necessarily includes analysing the shape of the chips. After each test, the chips were collected and examined from a geometrical and metallurgical point of view using an optical microscope. The second column of Fig. 14 shows the different chip morphologies obtained for different cutting conditions. It should be noted that the chip morphology depended strongly on the feed rate and slightly less on the cutting speed. For a feed rate of $0.1 \mathrm{~mm} / \mathrm{rev}$, the chips were observed to be continuous. However, when the feed rate was increased, the chips became increasingly discontinuous. These chips were formed by strain localization. This phenomenon, widely studied in machining, is called catastrophic shear or adiabatic shear band (Poulachon et al., 2005). For a slow feed rate, the chip generating mechanism involved the formation of a crack followed by slip in the crack plane.

\subsection{Numerical simulation of orthogonal cutting operations}

In the literature, different simulation methods are used to model machining operations: finite element method, meshless methods, etc. For the finite element method, depending on the assumptions used, different approaches are possible. In this work, 2D plane strain models were used with strong thermo-mechanical coupling. This procedure takes into account frictional heating and plastic dissipation. The cutting model included a rigid tool moving at constant speed and a deformable metal part using a thermo-visco-plastic constitutive model. The separation of nodes was possible via the use of a failure law including a damage initiation criterion and a damage evolution law (Mabrouki et al., 2008).

As part of this coupled problem, both mechanical and thermal contact properties must be defined. For the mechanical part, a frictional model with a Coulomb friction coefficient of 0.1 was used. For the thermal properties, a temperature increase due to friction was modelled with a conversion factor of 1.0 (i.e. 100\% of frictional energy converted to heat), and $50 \%$ of this energy was transmitted to the surface of the tool and 50\% to the machined surface. No heat exchange via conduction between the tool and the workpiece was modelled. It was assumed that this heat transfer mode is probably low given the geometry of the tool.

Concerning the boundary conditions, the lower surface of the workpiece was completely fixed (Fig. 15). The tool was considered to be rigid and isothermal, and moved with a constant speed in the negative $X$-direction (i.e. right to left horizontally). No movement in the $Y$-direction or rotation about the $Z$-axis was allowed. The initial temperature of the tool and workpiece was $293 \mathrm{~K}$.

The tool and workpiece were meshed using thermomechanical elements having both mechanical and thermal degrees of freedom. For the workpiece, two types of elements were used. For the tool and the zone of chip formation, quadrilateral CPE4RT elements were used (i.e. 6336 elements in the workpiece and 47 for the tool). For the rest of the workpiece, triangular CPE3T elements were used (3811 elements). The mesh was refined in the zone of chip formation and development. The elements of the tool were stiffened by adding a type constraint "isothermal rigid body". In order to reduce the computation time, a coarse mesh was used for the tool (Fig. 15). The commercial finite element code Abaqus Explicit 6.8 was used.

By observing the evolution of the temperature and the equivalent stress and strain, the process of chip formation, may be divided into three phases (Fig. 16): the initiation phase (a), the formation phase (b) and the propagation phase (c).

\subsection{Comparison between experimental and numerical results}

The purpose of this section is to discuss the effect of the different stress-strain constitutive models that take into account softening, on the chip formation process, for different cutting conditions. To this end, simulations were conducted on one hand, using a model that does not take into account this phenomenon (i.e. the Johnson-Cook model (Johnson and Cook, 1983)) and on the other hand, using models that accurately reproduced the phenomenon such as the TANH model (Calamaz et al., 2010), the Lurdos model (Lurdos, 2008) and the proposed model. The same damage model was used for all these simulations: it was the Johnson-Cook failure criterion (Johnson and Cook, 1985).

Other than the constitutive laws and friction, the predicted chip shape depended on the damage initiation and evolution parameters. The Johnson-Cook damage initiation criterion was identified in Hor (2011). The damage evolution criterion was based on fracture mechanics and it depended on some numerical parameters such as mesh size (Mabrouki et al., 2008). These parameters were adjusted by using the Johnson-Cook model to obtain chip shapes that are similar to the experimental observations for the same cutting conditions.

These parameters were then fixed for the other simulations, in which only the constitutive model was changed. Fig. 17 shows a comparison between the chip shape predicted using the different constitutive models. It is obvious that the chip shape which was closest to the experimen- 


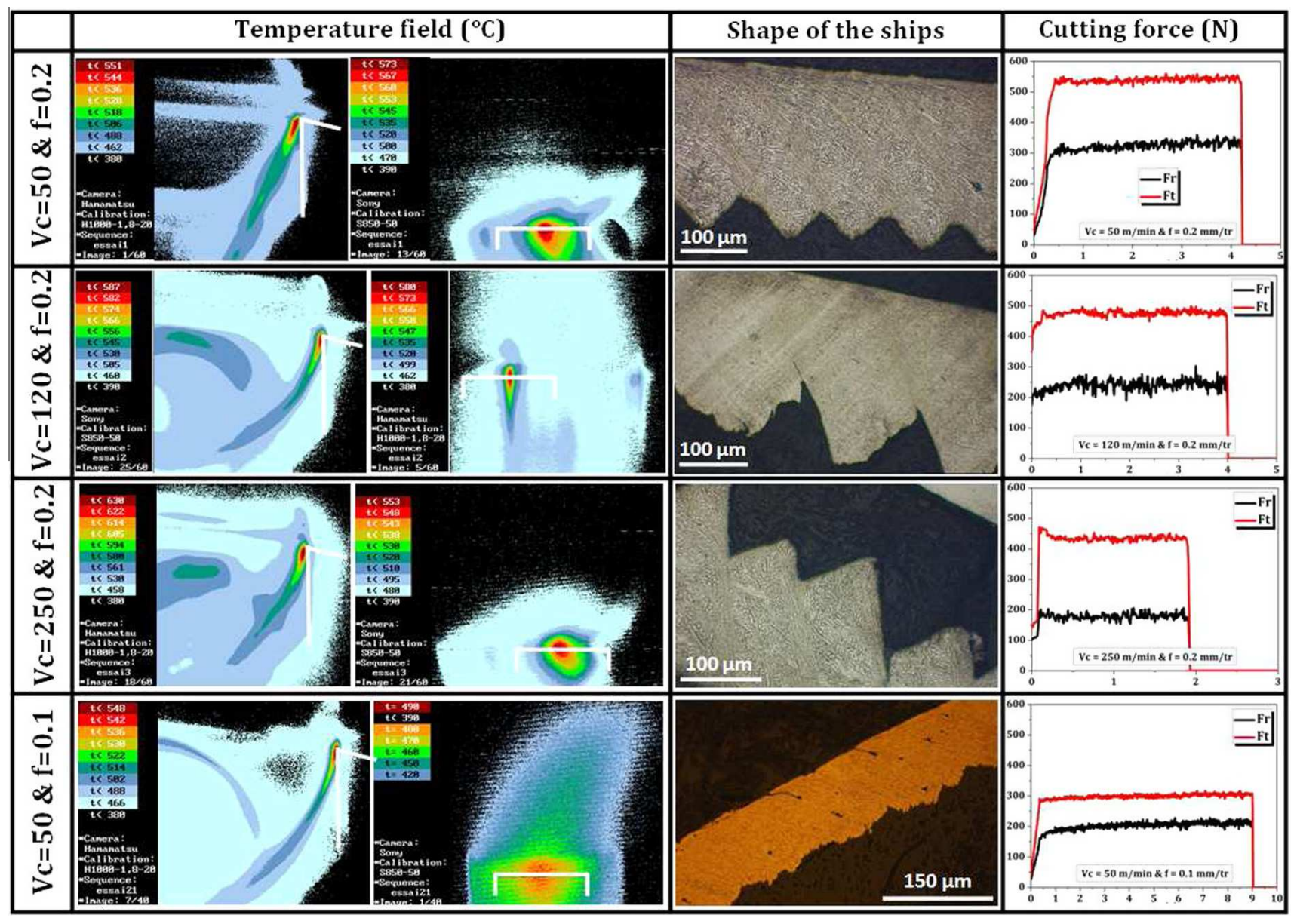

Fig. 14. Evolution of the temperature field $\left({ }^{\circ} \mathrm{C}\right)$, the cutting force $(\mathrm{N})$, and the chip shape as a function of the feed rate (mm/rev) and the cutting speed $(\mathrm{m} / \mathrm{min})$ for the machining of the $42 \mathrm{CrMo} 4-\mathrm{BA}$ steel.

tally observed shape was obtained using the Johnson-Cook model. This is because the principal parameters governing the chip formation process (i.e. the damage evolution parameters) were adjusted using this model. This comparison also shows that the most fragmented chip shapes were obtained using the TAHN and the proposed constitutive relations. These two models are characterized by a more significant softening (i.e. the slope of the stressstrain curve becomes negative for certain conditions). The introduction of the softening phenomenon in the constitutive equation improved the chip fragmentation. These observations were also made by Calamaz et al. (2010). Hence, softening plays a role that is similar to damage.

Comparison with experimental observations was made by evaluating the cutting forces and temperatures in the primary and secondary shear zones (Fig. 18). In terms of cutting forces, the four models studied in this section all overestimated the tangential force (Ft) and underestimated the radial force ( $\mathrm{Fr}$ ). This difference was due to inaccuracies in the frictional modelling. Nevertheless, a comparison between the tangential forces obtained in the various simulations was possible because the friction remained unchanged. This comparison shows, in particular, that the use of the Lurdos model or the proposed model improved the prediction of the cutting force. Indeed, the addition of softening in the TANH model reduced the cutting forces by $30 \%$. For the proposed model and the Lurdos model, this improvement was $35 \%$ and $37 \%$ respectively.

Concerning the temperature (see Fig. 18 on the right), it can be seen that the four constitutive models underestimated the temperature in the primary and secondary shear zones. This result explains the overestimation of the cutting forces previously discussed. In addition, the thermal predictions of the four models were very similar, the difference did not exceed $28^{\circ} \mathrm{C}$ in the primary shear zone and $47^{\circ} \mathrm{C}$ in the secondary shear zone. The fact that the predicted temperatures were lower than the experimentally observed values indicates that the identification of the stress-strain constitutive law based on compression tests could not properly account for certain effects such as the very localized self-heating observed in machining.

In order to improve the thermal predictions, the parameters of the Johnson-Cook equation were identified using shear test results obtained using "hat-shaped" specimens. The temperatures obtained in simulations using these parameters were similar or even higher than the experimental results. A comparison between the predicted temperatures obtained with two sets of parameters was undertaken. The first parameter set was obtained by direct identification (i.e. the second method) using the compression test results and the second parameter set was ob- 


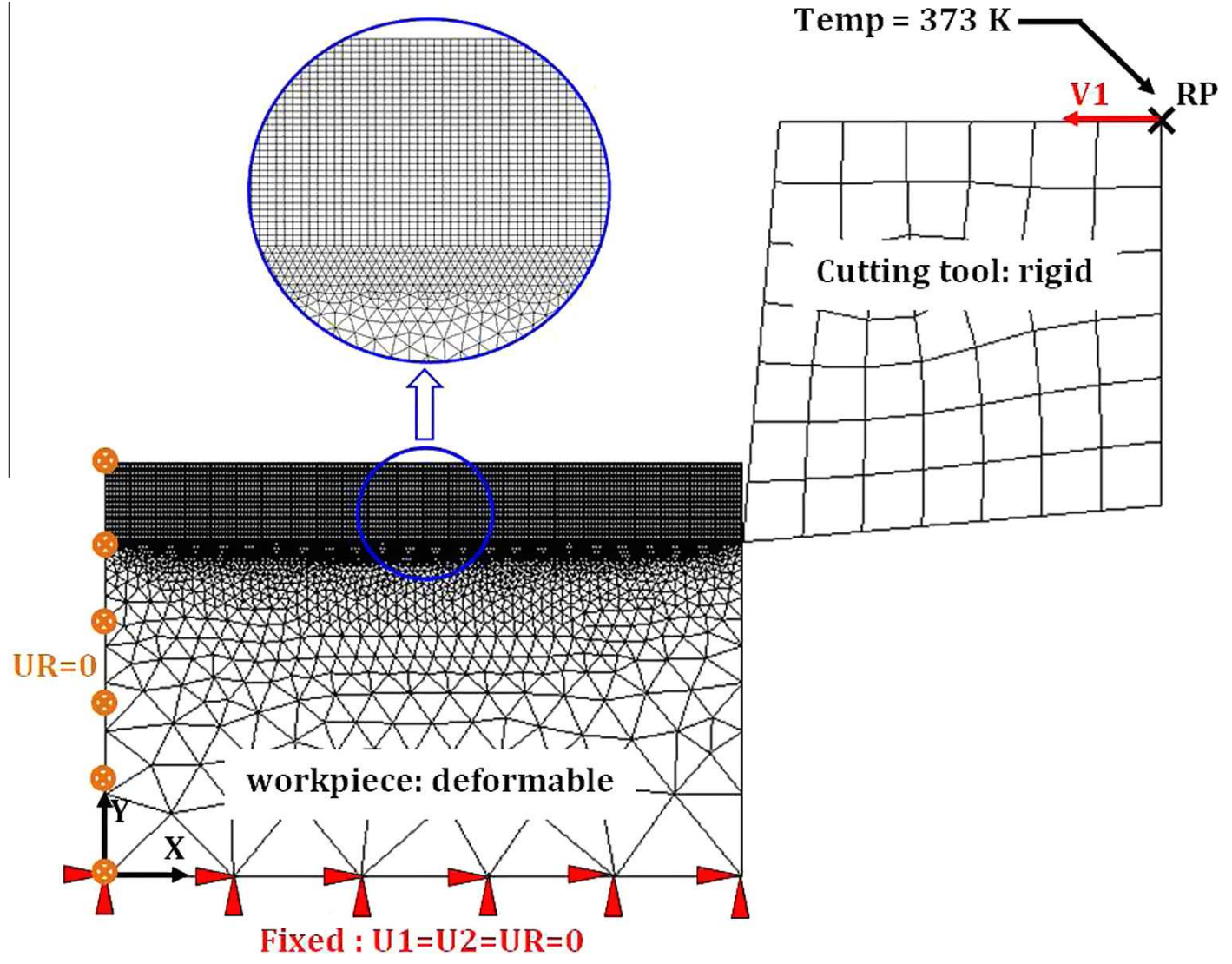

Fig. 15. Finite element model of chip formation in orthogonal cutting.

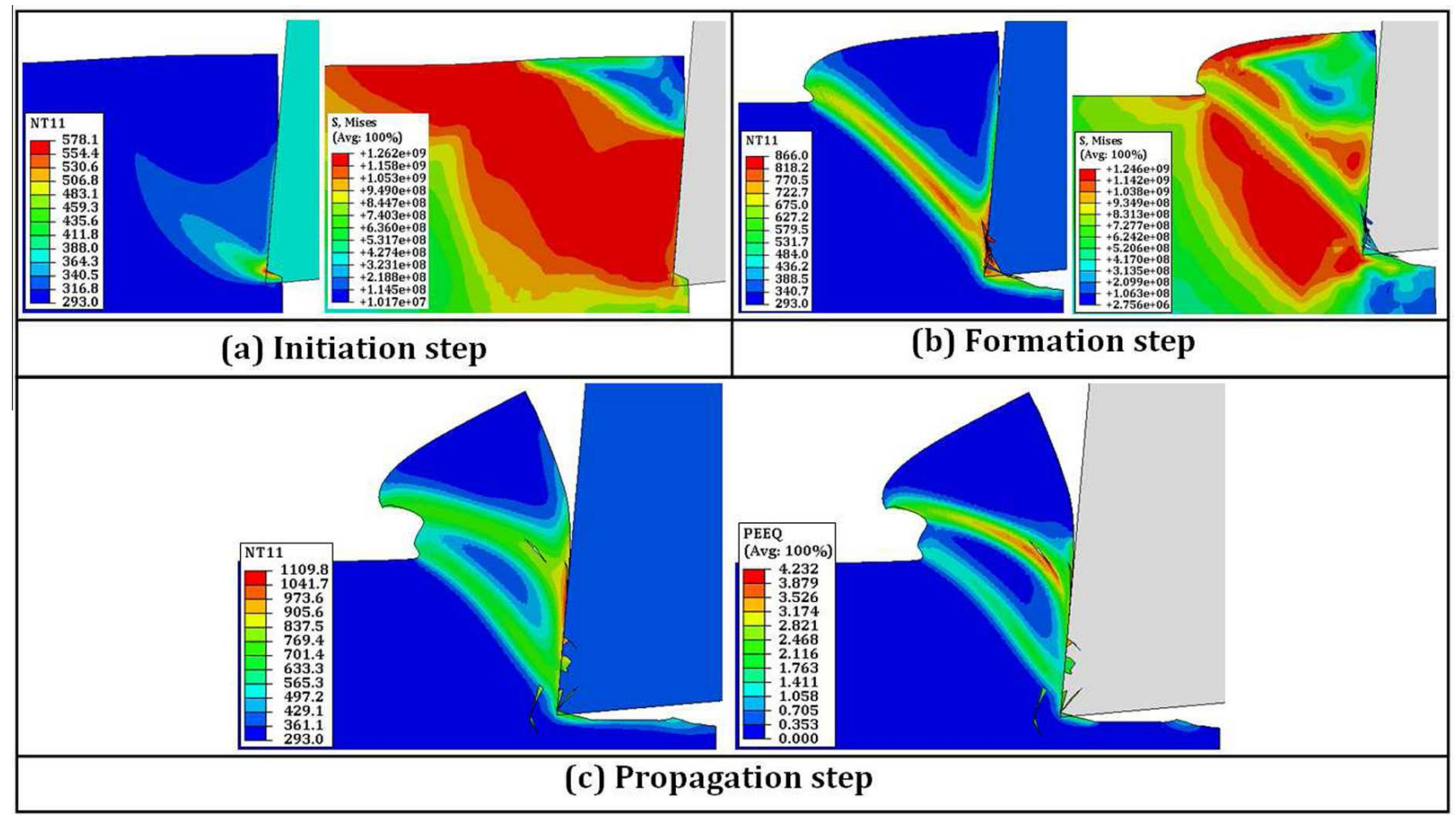

Fig. 16. Description of the chip formation process in the numerical simulation.

tained by an inverse identification method using the shear tests data (Table 12). This comparison showed that, for numerical simulations of machining operations using the
Johnson-Cook constitutive equation identified from the shear test data, the temperature increased from 659 to $764 \mathrm{~K}$ in the primary shear zone and 736 to $810 \mathrm{~K}$ in the 


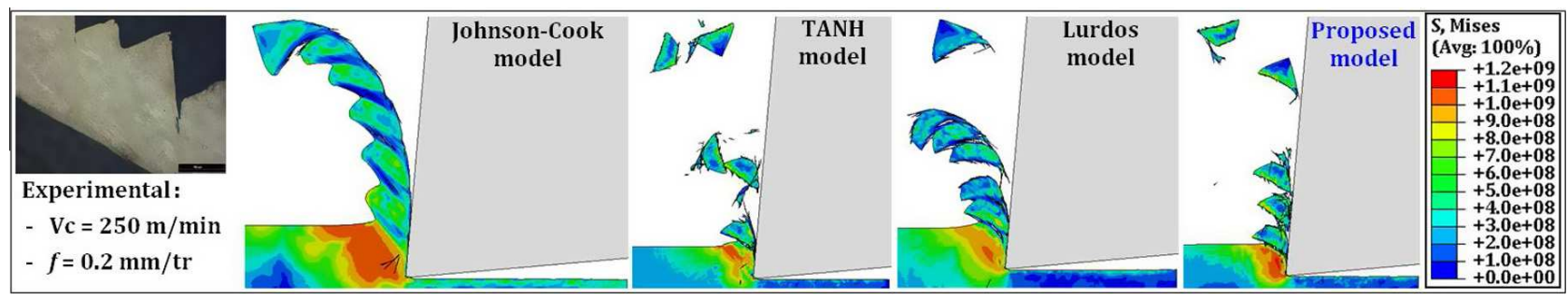

Fig. 17. Comparison between the chip shapes predicted using the different constitutive equations and the experimental chip shape for the following cutting conditions $V_{c}=250 \mathrm{~m} / \mathrm{min}$ and $f=0.2 \mathrm{~mm} / \mathrm{rev}$.
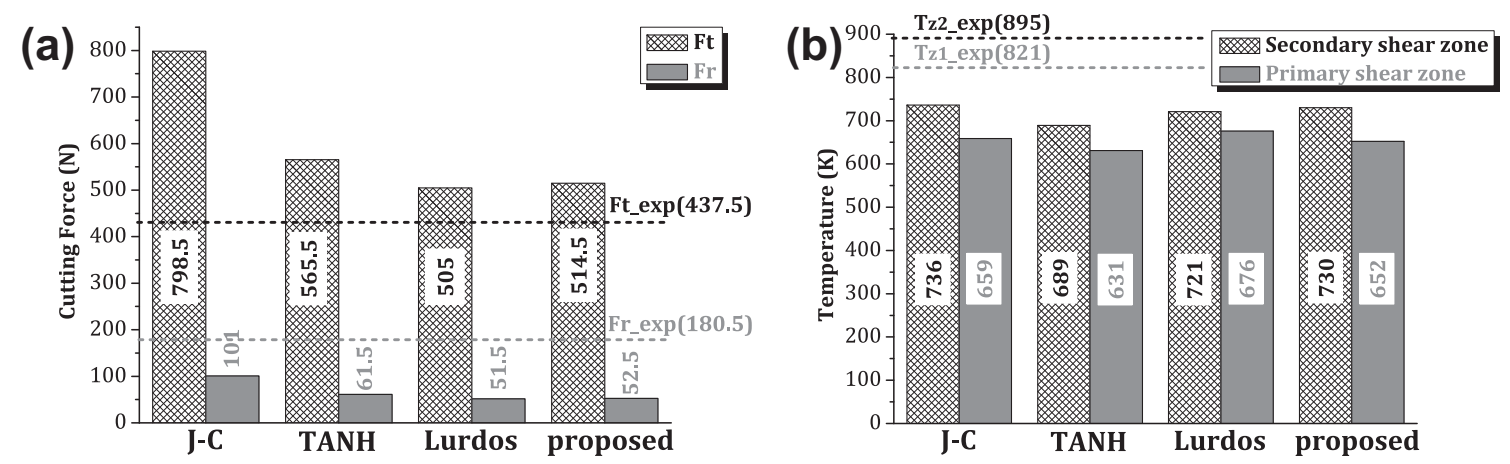

Fig. 18. Comparison between the cutting forces (on the left) and the temperatures (on the right) obtained via numerical simulation using different constitutive models and corresponding experimental observations for the cutting conditions: $V_{c}=250 \mathrm{~m} / \mathrm{min}$ and $f=0.2 \mathrm{~mm} / \mathrm{rev}$.

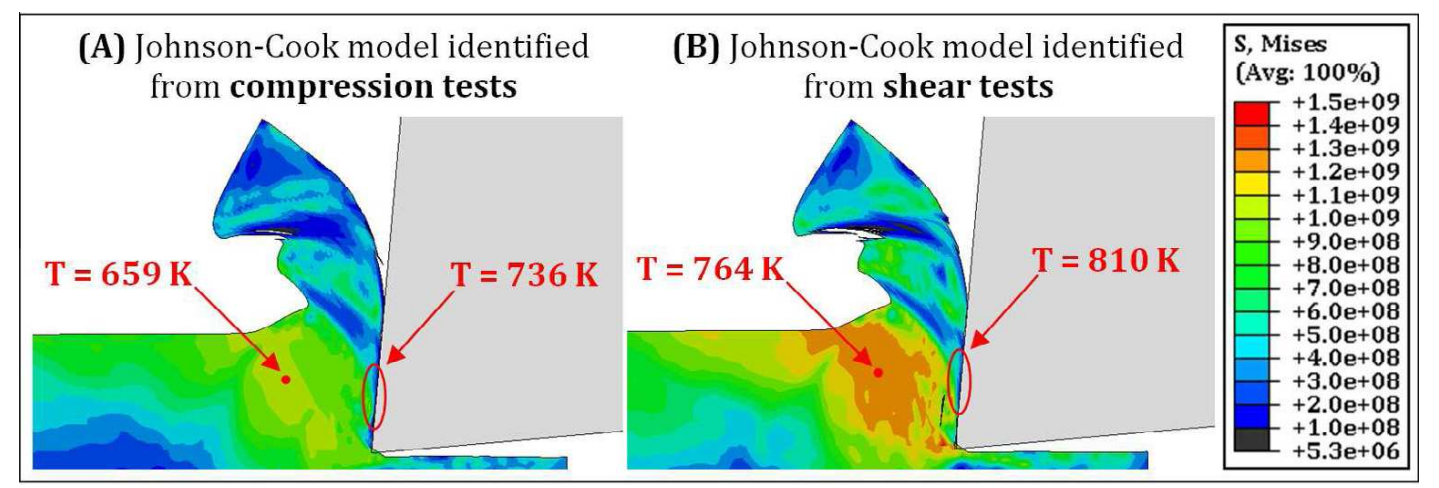

Fig. 19. Comparison between the chip shapes, the equivalent stress field and the temperatures in ZI and ZII obtained numerically using the Johnson-Cook constitutive equation: (A) identified using compression test data and (B) identified using shear test data, for the following cutting conditions: $V_{c}=250 \mathrm{~m} / \mathrm{min}$ and $f=0.2 \mathrm{~mm} / \mathrm{tr}$.

secondary shear zone (Fig. 19). These temperatures were close to the experimental observations $(821 \mathrm{~K}$ in $\mathrm{ZI}$ and $895 \mathrm{~K}$ in ZII). This justifies the underestimation of the temperature by the different constitutive models identified using the compression test data.

Finally, the use of empirical coupled constitutive models, such as the TANH, the Lurdos and the proposed model in the simulation of hat-shaped specimens and machining operations resulted in better chip fragmentation and improved the prediction of certain global measurements such as the cutting forces. The Lurdos model and the proposed model resulted in the best predictions of the tangential cutting forces and were 35-37\% lower than the predictions of the Johnson-Cook equation. However, the identification of these models using the compression test data underestimated some effects such as self-heating and localization, resulting in lower temperatures than the experimentally determined ones. This was the case for all of the constitutive models investigated. The simulation performed using the Johnson-Cook constitutive model had a larger cutting force but not reached larger temperature. This is due to the chip segmentation process. Indeed, the models with softening allow a greater increase in temperature, but the cutting force remained low due this segmentation process.

\section{Conclusion}

A major problem with studies concerning rheology in machining and forging is the lack of experimental data, which limits those wishing to numerically model and analyse these operations to the use of very simple models 
(such as the Johnson Cook model) (Barge et al., 2005; Mabrouki et al., 2008) whose identification requires only a few tests (Tounsi et al., 2002; Zemzemi et al., 2009). These constitutive models, once identified, have in general a very limited range of validity which does not cover the range of application of the machining process. In addition, very different parameters for the same materials can be found in the literature (Guo et al., 2006; Huang and Liang, 2003).

In this study, the limits of these constitutive models (especially the Johnson-Cook model) have been highlighted, through the use of a very rich experimental database. Also, the experimental and numerical reasons that can lead to large difference in their identification were discussed. More sophisticated empirical models were then investigated. These coupled models showed better accuracy but were sometimes very costly (in terms of the number of parameters), and their identification often required specific experimental or numerical manipulation. A coupled empirical model was developed and compared to these models. This comparison showed that it had a better cost-to-accuracy ratio. The comparison between these models and the experimental tests for three steels also showed that the increased number of experimental tests used for the identification improved the accuracy of their predictions. This was the case for all of the models investigated.

Finally, the application of these constitutive laws in the finite element modelling of machining operations showed that the inclusion of phenomena such as softening improved both qualitatively and quantitatively the accuracy of these simulations. It was also shown that using the parameters identified from experimental tests that simulated the process (shear tests in this case) increased the accuracy of these simulations and more closely simulated the phenomena experienced by the material during this process (i.e. localization and self-heating in this case).

\section{References}

Andrade, U., Meyers, M., Chokshi, A., 1994. Constitutive description of work and shock hardened copper. Scripta Metallurgica et Materiallia 30 (7), 933-938.

Bäker, M., 2006. Finite element simulation of high-speed cutting forces. Journal of Materials Processing Technology 172 (1), 117-126.

Barge, M., Hamdi, H., Rech, J., Bergheau, J.-M., 2005. Numerical modelling of orthogonal cutting: influence of numerical parameters. Journal of Materials Processing Technology 164-165, 1148-1153.

Bergstrom, Y., Roberts, W., 1971. The application of a dislocation model to dynamical strainageing in alpha Fe containing interstitial atoms. Acta Metallurgica 19 (8), 815-823.

Calamaz, M., Coupard, D., Girot, F., 2010. Numerical simulation of titanium alloy dry machining with a strain softening constitutive law. Machining Science and Technology 14 (2), 244-257.

Cowper, G., Symonds, P., 1957. Strain hardening and strain rate effects in the impact loading of cantilever beams. In: Rapport Technique, Brown University.

Guo, Y., Wen, Q., Woodbury, K., 2006. Dynamic material behavior modeling using internal state variable plasticity and its application in hard machining simulations. Journal of Manufacturing Science and Engineering, Transactions of the ASME 128 (3), 749-759.

Habak, M., Lebrun, J.-L., Morel, A., 2007. A study of the influence of the metallurgical state on shear band and white layer generation in 100cr6 steel: application to machining. In: Proceedings of the 10th ESAFORM Conference on Material Forming, pp. 691-696.

Hollomon, J., 1945. Tensile deformation. Transactions of the AIME 162, 268-290.
Holmquist, T., Johnson, G., 1991. Determination of constants and comparison of results for various constitutive models. Journal of Physique 1 (3), 853-860.

Hor, A., 2011. Simulation physique des conditions thermomécaniques de forgeage et d'usinage: caractérisation et modélisation de la rhéologie et de l'endommagement. Ph.D. thesis, Arts et Métiers ParisTech.

Hor, A., Morel, F., Lebrun, J.-L., Germain, G., 2013. An experimental investigation of the behaviour of steels over large temperature and strain rate ranges. International Journal of Mechanical Sciences 67, $108-122$.

Huang, Y., Liang, S., 2003. Force modelling in shallow cuts with large negative rake angle and large nose radius tools - application to hard turning. International Journal of Advanced Manufacturing Technology 22 (9-10), 626-632.

Johnson, G., Cook, W., 1983. A constitutive model and data for metals subjected to large strains, high strain rates and high temperatures. In: Proceedings of the 7th International Symposium on ballistics, The Hague, Netherlands.

Johnson, G., Cook, W., 1985. Fracture characteristics of three metals subjected to various strains, strain rates, temperatures and pressures. Engineering Fracture Mechanics 21, 31-48.

Khan, A.S., Liang, R., 1999. Behaviors of three bcc metal over a wide range of strain rates and temperatures: experiments and modeling. International Journal of Plasticity 15 (10), 1089-1109.

Klepaczko, J., 1987. A practical stress-strain-strain rate-temperature constitutive relations of the power form. Journal of Mechanical Working Technology 15, 143-164.

Kocks, U., 1976. Lows for work-hardening and low-temperature creep. Journal of Engineering Materials and Technology, 76-85.

Liang, R., Khan, A.S., 1999. A critical review of experimental results and constitutive models for bcc and fcc metals over a wide range of strain rates and temperatures. International Journal of Plasticity 15 (9), 963-980.

Litonsky, J., 1977. Bulletin de l'Académie Polonaise des Sciences 25 (7).

Ludwik, P., 1909. Applied Mechanik: Elemente der technologischen mechanik. Springer Verlag, Berlin.

Lurdos, O., 2008. Loi de comportement et recristallisation dynamique: approches empirique et physique. Ph.D. thesis, Ecole Nationale Supérieure des Mines de Saint-Etienne.

Mabrouki, T., Girardin, F., Asad, M., Rigal, J.-F., 2008. Numerical and experimental study of dry cutting for an aeronautic aluminium alloy (a2024-t351). International Journal of Machine Tools and Manufacture 48, 1187-1197.

Marquardt, D., 1963. An algorithm for the least squares estimation of nonlinear parameters. SIAM Journal 11, 431-441.

Merchant, E., 1945a. Mechanics of the metal cutting process. 1. Orthogonal cutting and a type 2 chip. Journal of Applied Physics 16 (5), 267-275.

Merchant, E., 1945b. Mechanics of the metal cutting process. 2. Plasticity conditions in orthogonal cutting. Journal of Applied Physics 16 (6), 318-324.

Meyers, M.A., Subhash, G., Kad, B.K., Prasad, L., 1994. Evolution of microstructure and shear-band formation in alpha-hcp titanium. Mechanics of Materials 17 (2-3), 175-193.

Montheillet, F., 1996. Métallurgie en mise en forme. Techniques de l'ingénieur M600, 1-20.

M'Saoubi, R., Lebrun, J.-L., Changeux, B., 1998. A new method for cutting tool temperature measurement using ccd infrared technique: influence of tool and coating. Machining Science and Technology 2 (2), 369-382.

Mulyadi, M., Rist, M.A., Edwards, L., Brooks, J.W., 2006. Parameter optimisation in constitutive equations for hot forging. Journal of Materials Processing Technology 117, 311-314.

Picart, P., 1986. Contribution à la résolution numérique des problèmes élastoplastiques et élastoviscoplastiques en transformations finies. Ph.D. thesis, Université de Valenciennes.

Poulachon, G., Albert, A., Schluraff, M., Jawahir, I., 2005. An experimental investigation of work material microstructure effects on white layer formation in PCBN hard turning. International Journal of Machine Tools and Manufacture 45 (2), 211-218.

Prager, W., 1955. The theory of plasticity: a survey of recent achievements. Proceedings of the Institution of Mechanical Engineers 169, 41-57.

Sellars, C., 1985. The kinetics of softening processes during hot working of austenite. Czechoslovak Journal of Physics B 35, 239-248.

Sokolowsky, V., 1948. Propagation of elasto-viscoplastic waves in bars. Prikladnaya Matematika i Mekhanika 12, 261-280.

Swift, H., 1952. Plastic instability under plane stress. Journal of the Mechanics and Physics of Solids 1, 1-18. 
Tounsi, N., Vincenti, J., Otho, A., Elbestawi, M., 2002. From the basic mechanics of orthogonal metal cutting toward the identification of the constitutive equation. International Journal of Machine Tools and Manufacture 42 (12), 1373-1383.

Vinh, T., Afzali, M., Roche, A., 1980. In: Miller, K.J., Smith, R.F. (Eds.), Mechanical Behaviour of Materials. Pergamon Press, Oxford and New York.

Voce, E., 1948. The relationship between stress and strain for homogeneous deformation. Journal of the Institute of Metals 74, 537-562.

Zemzemi, F., Rech, J., Salem, W.B., Dogui, A., Kapsa, P., 2009. Identification of a friction model at tool/chip/workpiece interfaces in dry machining of aisi4142 treated steels. Journal of Materials Processing Technology 209 (8), 3978-3990.

Zener, C., Holloman, J.H., 1944. Effect of strain rate upon plastic flow of steel. Journal of Applied Physics 15, 22-32.

Zerilli, F., Armstrong, R., 1987. Dislocation-mechanics-based constitutive relations for material dynamics calculations. Journal of Applied Mechanics 61 (5), 1816-1825.

Zhao, H., Gary, G., 1996. The testing and behaviour modelling of sheet metals at strain rate from $10^{-4}$ to $10^{5} \mathrm{~s}^{-1}$. Mater. Science Engineering 207 (1), 46-50. 